\title{
Ultradrawing and Ultimate Tenacity Properties of Ultrahigh Molecular Weight Polyethylene Composite Fibers Filled with Nanosilica Particles with Varying Specific Surface Areas
}

\author{
Jen-taut Yeh, ${ }^{1,2,3}$ Chuen-Kai Wang, ${ }^{2}$ Lu-Kai Huang, ${ }^{2}$ Chih-Chen Tsai, ${ }^{2}$ and Wei-Yu Lai ${ }^{3}$ \\ ${ }^{1}$ Hubei Collaborative Innovation Center for Advanced Organic Chemical Materials, Ministry of Education, \\ Key Laboratory for the Green Preparation and Application of Functional Materials, Faculty of Materials Science and Engineering, \\ Hubei University, Wuhan 430062, China \\ ${ }^{2}$ Graduate School of Material Science and Engineering, National Taiwan University of Science and Technology, Taipei 10607, Taiwan \\ ${ }^{3}$ Department of Materials Engineering, Kun Shan University, Tainan 71070, Taiwan
}

Correspondence should be addressed to Jen-taut Yeh; jyeh@mail.ntust.edu.tw

Received 14 April 2015; Revised 20 July 2015; Accepted 29 July 2015

Academic Editor: Bin Li

Copyright ( $\odot 2015$ Jen-taut Yeh et al. This is an open access article distributed under the Creative Commons Attribution License, which permits unrestricted use, distribution, and reproduction in any medium, provided the original work is properly cited.

\begin{abstract}
Original and/or functionalized nanosilica particles with a quoted specific surface area of 100,300 , and $600 \mathrm{~m}^{2} / \mathrm{g}$, respectively, were used to investigate the influence of specific surface areas of nanosilica particles on ultradrawing and ultimate tensile properties of ultrahigh molecular weight polyethylene (UHMWPE), UHMWPE/nanosilica, and UHMWPE/functionalized nanosilica fibers. The specific surface areas of well-dispersed functionalized nanosilica particles in UHMWPE/functionalized nanosilica fibers can positively affect their ultradrawing, orientation, ultimate tensile properties, and "micro-fibrils" morphologies. Excellent orientation and ultimate tensile properties of UHMWPE/nanofiller fibers can be prepared by ultradrawing the UHMWPE/functionalized nanosilica as-prepared fibers with optimal contents of the best prepared functionalized nanosilica particles well dispersing in the as-prepared fibers. The ultimate tensile strength value of the best prepared UHMWPE/functionalized nanosilica drawn fiber reaches 7.6 GPa, which is about 2.3 times of those of the best prepared UHMWPE drawn fiber without addition of any nanofiller. Specific surface area, morphological and Fourier transform infrared analyses of original and functionalized nanosilica particles, and/or investigations of thermal, orientation factor, and ultimate tensile properties of as-prepared and/or drawn UHMWPE/functionalized nanosilica fibers were performed to understand the above improved ultradrawing and ultimate tensile properties of the UHMWPE/functionalized nanosilica as-prepared and/or drawn fibers.
\end{abstract}

\section{Introduction}

As a kind of extremely significant and strategic material, ultrahigh molecular weight polyethylene (UHMWPE) fibers have attracted much attention for the last three decades, since they exhibit significantly higher tenacity but lower density values than those of other high performance fibers, such as carbon and aramid fibers [1-5]. Polyethylene fibers [1, 6-31] are typical high performance fibers produced using the gel spinning processing method from flexible polymer chains. Remarkable progress has been made in the improvement of these high performance fibers since then; however, the highest tensile strengths and moduli achieved for UHMWPE fibers are still well below the broad range of theoretical tensile strengths and moduli reported for the UHMWPE perfect crystals [1]. The highest tenacity of commercially available UHMWPE fibers reaches as high as $45 \mathrm{~g} / \mathrm{den}$ [32]; however, this obtained strength is still far below the theoretical achievable strength, $372 \mathrm{~g} / \mathrm{den}$ reported for the perfect polyethylene crystal [16]. The key element in obtaining high-strength UHMWPE fibers is to find a way to draw the as-prepared gel specimens to an ultrahigh draw ratio after the gel spinning process. The drawability of the as-prepared gel specimens was found to depend significantly on the compositions of solutions from which gels were made $[6,7,33]$. Several authors $[12-15,33]$ reported that the drawing temperature and rate 
could markedly affect the maximal achievable draw ratio and tensile properties of solution-grown UHMWPE samples. In addition to the gel solution compositions and drawing conditions, it is generally recognized that the conditions used in the formation process after spinning and/or solution casting of gel solutions can also have a significant influence on the morphology, microstructure, and drawing properties of the specimens formed during the above-mentioned processes $[7,9,14,17-23]$.

Our recent investigations [24-27] found that the achievable draw ratios (achievable $\lambda$ ) of UHMWPE/nanofillers as-prepared fibers prepared near the optimal UHMWPE concentration improve to a maximal value as their nanofillers contents reach an optimal value, respectively, in which, the nanofillers (e.g., carbon nanotube (CNT) [24], attapulgite [25], nanosilica and/or their functionalized nanofillers [26], and functionalized bacterial cellulose [27]) with extremely high specific surface areas can serve as efficient nucleation sites and facilitate the crystallization of UHMWPE molecules into crystals but with lower melting temperatures $\left(T_{m}\right)$ and/or evaluated smaller crystal thickness $\left(l_{c}\right)$ values during their crystallization processes. Presumably, the crystals with lower $T_{m}$ and/or evaluated smaller $l_{c}$ values obtained at proper plain and/or modified nanofiller contents can be melted and pulled out of folded lamellar crystals relatively easily during ultradrawing processes and hence this results in higher drawability and orientation of the UHMWPE/nanofillers or UHMWPE/modified nanofillers fibers. The maximal achievable draw ratios of UHMWPE/ nanofillers or UHMWPE/modified nanofillers as-prepared fiber specimens and the tensile strengths of the drawn UHMWPE/nanofillers or UHMWPE/modified nanofillers fiber specimens are significantly higher than those of the plain UHMWPE as-prepared and drawn fiber specimens prepared at the same draw ratios of UHMWPE concentrations but without addition of the nanofillers and/or modified nanofillers, respectively. The ultimate tensile strength values of UHMWPE/purified attapulgite, UHMWPE/functionalized CNT, UHMWPE/functionalized nanosilica, and UHMWPE/functionalized bacterial cellulose drawn fibers prepared using one-stage drawing process at $95^{\circ} \mathrm{C}$ can reach $4.7,5.8,7.0$, and $7.1 \mathrm{GN} \mathrm{m}^{-2}$, respectively, which is about $1.74,2.15,2.59$, and 2.63 times of that of the corresponding plain UHMWPE drawn fibers prepared at the same optimal UHMWPE concentration, formation, and drawing condition but without incorporation of modified nanofillers.

The above results clearly suggested that nanofillers with high specific surface areas can serve as efficient nucleation sites for crystallization of UHMWPE molecules and improve the ultradrawing and ultimate tensile properties of UHMWPE/nanofiller fibers. Among these nanofillers, nanosilica particles are cheap and commercially available for a wide range of specific surface areas. In this study, the ultradrawing and ultimate tensile properties of the UHMWPE/nanosilica and UHMWPE/functionalized nanosilica fibers with a wide range of specific surface areas were systematically investigated. The maximal achievable $\lambda$ and ultimate tensile strength values obtained for the best prepared UHMWPE/functionalized nanosilica as-prepared fibers are even higher than those of the best prepared UHMWPE/modified attapulgite, UHMWPE/functionalized $\mathrm{CNT}$, and UHMPE/functionalized bacterial cellulose as-prepared fibers prepared at the optimal modified attapulgite, functionalized CNT, and functionalized bacterial cellulose contents, respectively [24-27]. Specific surface area, morphological and Fourier transform infrared analyses of the original and functionalized nanosilica specimens, and/or investigations of thermal, orientation factor, and ultimate tensile properties of the as-prepared and drawn UHMWPE/ functionalized nanosilica fiber specimens were performed to understand the above improved ultradrawing and ultimate tensile properties of the UHMWPE/functionalized nanosilica as-prepared and/or drawn fibers.

\section{Experimental}

2.1. Materials and Sample Preparation. The UHMWPE GUR4120 resin used in this study is associated with a weight average molecular weight $(\mathrm{Mw})$ of $5.0 \times 10^{6}$, which was kindly supplied by Celanese (Nanjing) Diversified Chemical Corporation, Nanjing, China. Three types of nanosilica particles (Merck SSA-100, SSA-300, and SSA-600) used in this study were purchased from Lu Ming Nanomaterials Corporation, Dalian, China. The specific surface areas of SSA-100, SSA300 , and SSA-600 nanosilica (NSI) particles were quoted as 90-105 $\mathrm{m}^{2} / \mathrm{g}, 285-305 \mathrm{~m}^{2} / \mathrm{g}$, and $580-610 \mathrm{~m}^{2} / \mathrm{g}$, respectively, by Lu Ming Nanomaterials Corporation. Functionalized nanosilica (FNSI) particles were prepared by grafting maleic anhydride grafted polyethylene ( $\left.\mathrm{PE}_{\mathrm{g}-\mathrm{MAH}}\right)$ molecules onto NSI particles in ultrasonicated mixtures of decalin, NSI, and $\mathrm{PE}_{\mathrm{g}-\mathrm{MAH}}$ at $170^{\circ} \mathrm{C}$ for 1 hour, in which, $\mathrm{PE}_{\mathrm{g}-\mathrm{MAH}}$ resin was purchased from Langfang Plastic Corporation, Langfang, China. The nanosilica and functionalized nanosilica particles prepared above are referred to as $\mathrm{NSI}^{x}$ and $\mathrm{FNSI}_{\mathrm{m} y}^{x}$, respectively, in the following discussion, in which, the superscript $x$ denotes the quoted specific surface areas of virgin NSI nanosilica particles and the subscript $y$ denotes the weight ratio of $\mathrm{PE}_{\mathrm{g}-\mathrm{MAH}}$ to $\mathrm{NSI}^{x}$ used in the preparation processes of $\mathrm{FNSI}_{\mathrm{m} y}^{x}$ functionalized nanosilica particles. Table 1 summarized designations and compositions of typical nanosilica and functionalized nanosilica particles prepared in this study.

Varying contents of $\mathrm{NSI}^{x}$ and $\mathrm{FNSI}^{x}{ }_{\mathrm{m} y}$ particles together with UHMWPE resin were dispersed and dissolved in decalin at $135^{\circ} \mathrm{C}$ for 1.5 hours, in which $0.1 \%$ di-t-butyl-p-cresol was added as an antioxidant. The UHMWPE, UHMWPE/NSI ${ }^{x}$, and UHMWPE/FNSI ${ }^{x}{ }_{\mathrm{m} y}$ gel solutions prepared above were then fed into a temperature-controlled hopper and kept as hot homogenized gel solutions before spinning. The hot homogenized gel solutions were then gel-spun using a conical die with an exit diameter of $1 \mathrm{~mm}$ at an extrusion rate of $1000 \mathrm{~mm} / \mathrm{min}$ and an extrusion temperature of $170^{\circ} \mathrm{C}$. A water bath and a winder with $70 \mathrm{~mm}$ in diameter were placed at a distance of $520 \mathrm{~mm}$ and $810 \mathrm{~mm}$ from the spinneret exit, respectively. The extruded gel fibers were cooled in a temperature-conditioned atmosphere and then quenched into a water bath for about 1 minute, where the temperature 
TABLE 1: Designations, compositions, and specific surface areas of nanosilica particles $\left(\mathrm{NSI}^{x}\right)$ and functionalized nanosilica particles $\left(\mathrm{FNSI}_{\mathrm{m} y}^{x}\right.$ ) prepared in this study.

\begin{tabular}{lcc}
\hline $\begin{array}{l}\mathrm{NSI}^{x} \text { and FNSI } \\
\text { specimens }\end{array}$ & $\begin{array}{c}\text { Mass ratios of } \\
\mathrm{PE}_{\mathrm{g}-\mathrm{MAH}} \text { to NSI }\end{array}$ & $\begin{array}{c}\text { Specific surface areas } \\
\left(\mathrm{m}^{2} / \mathrm{g}\right)\end{array}$ \\
\hline $\mathrm{NSI}^{100}$ & 0.0 & 102.3 \\
$\mathrm{FNSI}^{100}{ }_{\mathrm{m} 1}$ & 1.0 & 109.7 \\
$\mathrm{FNSI}^{100}{ }_{\mathrm{m} 2}$ & 2.0 & 114.8 \\
$\mathrm{FNSI}^{100}{ }_{\mathrm{m} 3}$ & 3.0 & 129.8 \\
$\mathrm{FNSI}^{100}{ }_{\mathrm{m} 6}$ & 6.0 & 122.4 \\
$\mathrm{FNSI}^{100}{ }_{\mathrm{m} 12}$ & 12.0 & 109.6 \\
\hline $\mathrm{NSI}^{300}{ }^{300}$ & 0.0 & 303.9 \\
$\mathrm{FNSI}^{300}{ }_{\mathrm{m} 2}$ & 2.0 & 314.5 \\
$\mathrm{FNSI}^{300}{ }_{\mathrm{m} 3}$ & 3.0 & 325.5 \\
$\mathrm{FNSI}^{300}{ }_{\mathrm{m} 6}$ & 6.0 & 335.8 \\
$\mathrm{FNSI}^{300}{ }_{\mathrm{m} 9}$ & 9.0 & 330.8 \\
$\mathrm{FNSI}^{300}{ }_{\mathrm{m} 12}$ & 12.0 & 315.3 \\
\hline $\mathrm{NSI}^{600}{ }_{\mathrm{m}}{ }_{\mathrm{m}}$ & 0.0 & 601.7 \\
$\mathrm{FNSI}^{600}{ }_{\mathrm{m} 2}$ & 2.0 & 617.4 \\
$\mathrm{FNSI}^{600}{ }_{\mathrm{m} 3}$ & 3.0 & 621.4 \\
$\mathrm{FNSI}^{600}{ }_{\mathrm{m} 6}$ & 6.0 & 625.3 \\
$\mathrm{FNSI}^{600}{ }_{\mathrm{m} 9}$ & 9.0 & 630.7 \\
$\mathrm{FNSI}^{600}{ }_{\mathrm{m} 12}$ & 12.0 & 621.4 \\
\hline
\end{tabular}

of the air atmosphere and water bath was controlled at $5^{\circ} \mathrm{C}$. The quenched fibers were then extracted in $\mathrm{n}$-hexane bath for 5 minutes to remove the residual decalin solvent. The extracted fiber specimens were then dried in air for 30 minutes to remove the remaining $n$-hexane solvent before any drawing run. The UHMWPE, UHMWPE/NSI ${ }^{x}$, and UHMWPE/FNSI ${ }^{x}$ m as-prepared fiber specimens prepared above are referred to as $\mathrm{F}_{100}, \mathrm{~F}_{100} \mathrm{NSI}^{x}{ }_{z}$, and $\mathrm{F}_{100} \mathrm{FNSI}^{x}{ }_{\mathrm{m} y-z}$ as-prepared fiber specimens, respectively, in the following discussion, in which, the superscript $x$ denotes the quoted specific surface areas of varying $\mathrm{NSI}^{x}$ particles used to prepare $\mathrm{NSI}^{x}$ and $\mathrm{FNSI}^{x}{ }_{\mathrm{m} y}$ particles in $\mathrm{F}_{100} \mathrm{NSI}^{x}{ }_{z}$ and $\mathrm{F}_{100} \mathrm{FNSI}_{\mathrm{m} y-z}^{x}$ as-prepared fiber specimens, respectively; the subscript 100 denotes one hundred parts of UHMWPE resins used in the as-prepared fibers; $y$ denotes the weight ratio of $\mathrm{PE}_{\mathrm{g}-\mathrm{MAH}}$ to $\mathrm{NSI}^{x}$ used in the preparation processes of $\mathrm{FNSI}^{x}{ }_{\mathrm{m} y}$ fillers, while the subscript $z$ denotes parts of $\mathrm{NSI}^{x}$ or $\mathrm{FNSI}_{\mathrm{m} y}^{x}$ fillers used in per hundred parts of UHMWPE resins in the as-prepared fibers. Table 2 summarized designations of typical UHMWPE, UHMWPE/nanosilica, and UHMWPE/functionalized nanosilica as-prepared fiber specimens and the corresponding compositions of gel solutions used in the gel spinning processes.

2.2. Fourier Transform Infrared Spectroscopy. Fourier transform infrared (FTIR) spectroscopic measurements of $\mathrm{NSI}^{x}$ or $\mathrm{FNSI}_{\text {my }}^{x}$ specimens with varying specific surface areas were recorded on a Nicolet Avatar 360 FTIR spectrophotometer at $25^{\circ} \mathrm{C}$, wherein 32 scans with a spectral resolution $1 \mathrm{~cm}^{-1}$ were collected during each spectroscopic measurement. Infrared spectra of $\mathrm{NSI}^{x}$ or $\mathrm{FNSI}^{x}{ }_{\mathrm{m} y}$ film specimens were determined using the conventional $\mathrm{KBr}$ disk method. Alcohol and decalin solutions containing $\mathrm{NSI}^{x}$ or $\mathrm{FNSI}^{x}{ }_{\text {my }}$ particles, respectively, were cast onto $\mathrm{KBr}$ disk and dried at $60^{\circ} \mathrm{C}$ for 30 minutes. The cast films used in this study were prepared sufficiently thin enough to obey the Beer-Lambert law.

2.3. Morphological Analyses. In order to understand the morphology on the surfaces of $\mathrm{NSI}^{x}$ or $\mathrm{FNSI}^{x}{ }_{\mathrm{m} y}$ particles with varying specific surface areas prepared in Materials and Sample Preparation, NSI $^{x}$ particles were dispersed in alcohol, while $\mathrm{FNSI}^{x}{ }_{\mathrm{m} y}$ particles were dispersed in decalin to have a better dispersed morphology before examination. Before morphological analyses, ten micrograms of $\mathrm{NSI}^{x}$ or $\mathrm{FNSI}^{x}{ }_{\mathrm{m} y}$ particles was added and ultrasonicated in $10 \mathrm{~mL}$ alcohol and decalin at $25^{\circ} \mathrm{C}$ for 5 minutes, respectively. The dispersed particles were then dried onto a carbon-coated copper grid under ambient conditions prior to morphological analyses. The cast $\mathrm{NSI}^{x}$ or $\mathrm{FNSI}^{x}{ }_{\mathrm{m} y}$ particles were then examined using a Philip transmission electron microscope (TEM) model Tecnai G20 operated at $200 \mathrm{kV}$.

2.4. Specific Surface Area Analyses. A Laser Particle Size Analyzer model BT-9300H (Dandong Bettersize Instruments Corporation, Dandong, China) was used to study the specific surface areas of $\mathrm{NSI}^{x}$ or $\mathrm{FNSI}^{x}{ }_{\mathrm{m} y}$ particles with varying specific surface areas. Before analyses, ten micrograms of $\mathrm{NSI}^{x}$ or $\mathrm{FNSI}^{x}{ }_{\mathrm{m} y}$ particles was added and ultrasonicated in $10 \mathrm{~mL}$ alcohol and decalin at $25^{\circ} \mathrm{C}$ for 5 minutes, respectively. The specific surface areas of $\mathrm{NSI}^{x}$ or $\mathrm{FNSI}^{x}{ }_{\mathrm{m} y}$ particles were then measured by placing the ultrasonicated solutions prepared above in the curette of the Laser Particle Size Analyzer at $25^{\circ} \mathrm{C}$.

2.5. Thermal and Orientation Factor Analyses. Thermal properties of all as-prepared fiber specimens were performed on a Du Pont differential scanning calorimeter (DSC) model 2000. All scans were carried out at a heating rate of $20^{\circ} \mathrm{C} / \mathrm{min}$ under flowing nitrogen at a flow rate of $25 \mathrm{~mL} / \mathrm{min}$. Samples weighing $0.5 \mathrm{mg}$ and $15 \mathrm{mg}$ were placed in the standard aluminum sample pans for determination of their melting temperature $\left(T_{m}\right)$ and percentage crystallinity $\left(X_{c}\right)$ values, respectively. The percentage crystallinity values of the as-prepared fiber specimens were estimated using baselines drawn from 40 to $200^{\circ} \mathrm{C}$ and a perfect heat of fusion of polyethylene of $293 \mathrm{~J} / \mathrm{g}[28]$.

In order to understand the ultradrawing properties of UHMWPE, UHMWPE/NSI ${ }^{x}$, and UHMWPE/FNSI ${ }^{x}{ }_{\mathrm{m} y}$ asprepared fiber specimens, the lamellar thickness $\left(l_{c}\right)$ values of the above as-prepared fibers were evaluated from their $T_{m}$ values using Hoffman and Weeks' equation $[28,29]$ given in (1) as follows, in which, an equilibrium melting temperature $\left(T_{m}{ }^{o}\right)$ of $145.5^{\circ} \mathrm{C}$, a perfect heat of fusion $\left(\Delta H_{f}{ }^{0}\right)$ of $293 \mathrm{~J} / \mathrm{g}$, and a folded surface free energy $\left(\sigma_{e}\right)$ of $9 \times 10^{-6} \mathrm{~J} / \mathrm{cm}^{2}$ of polyethylene crystals [28] were used for evaluation of $l_{c}$ values 
TABLE 2: Designations, melting temperatures $\left(T_{m}\right)$, percentage crystallinity $\left(X_{c}\right)$, and evaluated lamellar thickness $\left(l_{c}\right)$ values of UHMWPE, typical UHMWPE/nanosilica, and UHMWPE/functionalized nanosilica as-prepared fiber specimens and corresponding compositions of gel solutions used in the gel spinning processes.

\begin{tabular}{|c|c|c|c|c|c|c|c|}
\hline As-prepared fiber specimens & $\begin{array}{c}\text { Original } \\
\text { nanosilica } \\
(\mathrm{g} / \mathrm{phr})\end{array}$ & $\begin{array}{c}\text { Functionalized } \\
\text { nanosilica (g/phr) }\end{array}$ & $\begin{array}{l}\text { UHMWPE } \\
\text { (g/phr) }\end{array}$ & $\begin{array}{c}\text { Volumes of } \\
\text { decalin in gel } \\
\text { solutions }(\mathrm{mL})\end{array}$ & $\begin{array}{l}T_{m} \\
\left({ }^{\circ} \mathrm{C}\right)\end{array}$ & $\begin{array}{l}X_{c} \\
(\%)\end{array}$ & $\begin{array}{c}l_{c} \\
(\mathrm{~nm})\end{array}$ \\
\hline$\overline{\mathrm{F}_{100}}$ & 0 & - & $2 / 100$ & 100 & 142.7 & 65.1 & 30.7 \\
\hline $\mathrm{F}_{100} \mathrm{NSI}_{0.05}^{100}$ & $0.001 / 0.05$ & - & $2 / 100$ & 100 & 141.1 & 67.8 & 25.6 \\
\hline $\mathrm{F}_{100} \mathrm{NSI}_{0.1}^{100}$ & $0.002 / 0.1$ & - & $2 / 100$ & 100 & 140.2 & 70.1 & 17.5 \\
\hline $\mathrm{F}_{100} \mathrm{NSI}^{100}{ }_{0.125}$ & $0.0025 / 0.125$ & - & $2 / 100$ & 100 & 141.9 & 66.0 & 18.2 \\
\hline $\mathrm{F}_{100} \mathrm{NSI}_{0.0375}^{300}$ & $0.00075 / 0.0375$ & - & $2 / 100$ & 100 & 140.9 & 68.3 & 22.5 \\
\hline $\mathrm{F}_{100} \mathrm{NSI}_{0.0625}^{300}$ & $0.00125 / 0.0625$ & - & $2 / 100$ & 100 & 140.2 & 70.8 & 17.5 \\
\hline $\mathrm{F}_{100} \mathrm{NSI}_{0.1}^{300}$ & $0.002 / 0.1$ & - & $2 / 100$ & 100 & 141.1 & 67.8 & 22.5 \\
\hline $\mathrm{F}_{100} \mathrm{NSI}^{600}{ }_{0.0375}$ & $0.00075 / 0.0375$ & - & $2 / 100$ & 100 & 140.7 & 69.1 & 19.3 \\
\hline $\mathrm{F}_{100} \mathrm{NSI}^{600}{ }_{0.05}$ & $0.001 / 0.05$ & - & $2 / 100$ & 100 & 139.9 & 71.5 & 15.7 \\
\hline $\mathrm{F}_{100} \mathrm{NSI}_{0.1}^{600}$ & $0.002 / 0.1$ & - & $2 / 100$ & 100 & 140.8 & 67.8 & 22.1 \\
\hline $\mathrm{F}_{100} \mathrm{FNSI}^{100}{ }_{\mathrm{m} 2-0.0375}$ & - & $0.00075 / 0.0375$ & $2 / 100$ & 100 & 141.6 & 66.2 & 25.8 \\
\hline $\mathrm{F}_{100} \mathrm{FNSI}^{100}{ }_{\mathrm{m} 2-0.075}$ & - & $0.0015 / 0.075$ & $2 / 100$ & 100 & 139.3 & 70.3 & 15.1 \\
\hline $\mathrm{F}_{100} \mathrm{FNSI}^{100}{ }_{\mathrm{m} 2-0.1}$ & - & $0.002 / 0.1$ & $2 / 100$ & 100 & 139.5 & 69.0 & 15.4 \\
\hline $\mathrm{F}_{100} \mathrm{FNSI}_{\mathrm{m} 3-0.0375}^{100}$ & - & $0.00075 / 0.0375$ & $2 / 100$ & 100 & 140.7 & 69.1 & 17.5 \\
\hline $\mathrm{F}_{100} \mathrm{FNSI}^{100}{ }_{\mathrm{m} 3-0.075}$ & - & $0.0015 / 0.075$ & $2 / 100$ & 100 & 138.3 & 75.4 & 12.4 \\
\hline $\mathrm{F}_{100} \mathrm{FNSI}_{\mathrm{m} 3-0.1}^{100}$ & - & $0.002 / 0.1$ & $2 / 100$ & 100 & 138.9 & 75.1 & 13.5 \\
\hline $\mathrm{F}_{100} \mathrm{FNSI}^{100}{ }_{\mathrm{m} 6-0.0375}$ & - & $0.00075 / 0.0375$ & $2 / 100$ & 100 & 140.9 & 68.9 & 22.5 \\
\hline $\mathrm{F}_{100} \mathrm{FNSI}_{\mathrm{m} 6-0.075}^{100}$ & - & $0.0015 / 0.075$ & $2 / 100$ & 100 & 139.2 & 72.4 & 14.1 \\
\hline $\mathrm{F}_{100} \mathrm{FNSI}^{100}{ }_{\mathrm{m} 6-0.1}$ & - & $0.002 / 0.1$ & $2 / 100$ & 100 & 139.6 & 71.3 & 14.7 \\
\hline $\mathrm{F}_{100} \mathrm{FNSI}_{\mathrm{m} 3-0.025}^{300}$ & - & $0.0005 / 0.025$ & $2 / 100$ & 100 & 139.5 & 73.2 & 14.6 \\
\hline $\mathrm{F}_{100} \mathrm{FNSI}_{\mathrm{m} 3-0.05}^{300}$ & - & $0.001 / 0.05$ & $2 / 100$ & 100 & 138.6 & 74.0 & 13.1 \\
\hline $\mathrm{F}_{100} \mathrm{FNSI}_{\mathrm{m} 3-0.075}^{300}$ & - & $0.0015 / 0.075$ & $2 / 100$ & 100 & 139.3 & 73.4 & 14.2 \\
\hline $\mathrm{F}_{100} \mathrm{FNSI}^{300}{ }_{\mathrm{m} 6-0.025}$ & - & $0.0005 / 0.025$ & $2 / 100$ & 100 & 138.5 & 75.2 & 12.7 \\
\hline $\mathrm{F}_{100} \mathrm{FNSI}_{\mathrm{m} 6-0.05}^{300}$ & - & $0.001 / 0.05$ & $2 / 100$ & 100 & 137.6 & 76.0 & 11.3 \\
\hline $\mathrm{F}_{100} \mathrm{FNSI}^{300}{ }_{\mathrm{m} 6-0.075}$ & - & $0.0015 / 0.075$ & $2 / 100$ & 100 & 138.3 & 75.4 & 12.4 \\
\hline $\mathrm{F}_{100} \mathrm{FNSI}_{\mathrm{m} 9-0.025}^{300}$ & - & $0.0005 / 0.025$ & $2 / 100$ & 100 & 139.0 & 74.1 & 13.6 \\
\hline $\mathrm{F}_{100} \mathrm{FNSI}_{\mathrm{m} 9-0.05}^{300}$ & - & $0.001 / 0.05$ & $2 / 100$ & 100 & 138.1 & 75.0 & 12.0 \\
\hline $\mathrm{F}_{100} \mathrm{FNSI}_{\mathrm{m} 9-0.075}^{300}$ & - & $0.0015 / 0.075$ & $2 / 100$ & 100 & 138.8 & 73.9 & 13.5 \\
\hline $\mathrm{F}_{100} \mathrm{FNSI}_{\mathrm{m} 3-0.025}^{600}$ & - & $0.0005 / 0.025$ & $2 / 100$ & 100 & 137.8 & 74.2 & 11.6 \\
\hline $\mathrm{F}_{100} \mathrm{FNSI}_{\mathrm{m} 3-0.0375}^{600}$ & - & $0.00075 / 0.0375$ & $2 / 100$ & 100 & 137.2 & 74.8 & 10.7 \\
\hline $\mathrm{F}_{100} \mathrm{FNSI}_{\mathrm{m} 3-0.075}^{600}$ & - & $0.0015 / 0.075$ & $2 / 100$ & 100 & 138.3 & 73.7 & 12.4 \\
\hline $\mathrm{F}_{100} \mathrm{FNSI}_{\mathrm{m} 9-0.025}^{600}$ & - & $0.0005 / 0.025$ & $2 / 100$ & 100 & 136.5 & 76.2 & 10.7 \\
\hline $\mathrm{F}_{100} \mathrm{FNSI}_{\mathrm{m} 9-0.0375}$ & - & $0.00075 / 0.0375$ & $2 / 100$ & 100 & 136.1 & 76.8 & 9.5 \\
\hline $\mathrm{F}_{100} \mathrm{FNSI}^{600}{ }_{\mathrm{m} 9-0.075}$ & - & $0.0015 / 0.075$ & $2 / 100$ & 100 & 137.0 & 75.9 & 10.1 \\
\hline $\mathrm{F}_{100} \mathrm{FNSI}_{\mathrm{m} 12-0.025}^{600}$ & - & $0.0005 / 0.025$ & $2 / 100$ & 100 & 137.3 & 74.7 & 11.1 \\
\hline $\mathrm{F}_{100} \mathrm{FNSI}_{\mathrm{m} 12-0.0375}^{600}$ & - & $0.00075 / 0.0375$ & $2 / 100$ & 100 & 136.7 & 75.3 & 9.8 \\
\hline $\mathrm{F}_{100} \mathrm{FNSI}_{\mathrm{m} 12-0.075}^{600}$ & - & $0.0015 / 0.075$ & $2 / 100$ & 100 & 137.8 & 74.3 & 11.6 \\
\hline
\end{tabular}

of UHMWPE, UHMWPE/NSI, and UHMWPE/FNSI asprepared fiber specimens:

$$
T_{m}=T_{m}{ }^{o}\left[1-\frac{2 \sigma_{e}}{l_{c} \Delta H_{f}{ }^{0}}\right] .
$$

The orientation factor $\left(f_{0}\right)$ values of UHMWPE, UHMWPE/NSI ${ }^{x}$, and UHMWPE/FNSI ${ }_{m y}$ as-prepared and drawn fiber specimens were measured using a sonic velocity orientation instrument model SCY-III, which was purchased from Donghuakaili Chemicals and Fiber Technology Corporation, Shanghai, China. Before testing, the fiber 
specimen with $60 \mathrm{~cm}$ in length was wound and clamped on a testing device with a span of $40 \mathrm{~cm}$. $f_{0}$ values of the as-spun and drawn fiber specimens were then measured at $25^{\circ} \mathrm{C}$. A minimum of five samples of each specimen were tested and averaged during $f_{0}$ measurements. $f_{0}$ values were evaluated using (2) as suggested by Xiao and coauthors [30]:

$$
f_{s}=1-\left(\frac{C_{u}}{C}\right)^{2},
$$

where $C$ is the sonic velocity of the as-prepared or drawn UHMWPE fiber specimen and $C_{u}$ is the sonic velocity of the fully unoriented sample, taken as $1.65 \mathrm{~km} / \mathrm{s}$ [30].

\subsection{Drawing and Tensile Properties of Fiber Specimens.} The UHMWPE, UHMWPE/NSI ${ }^{x}$, and UHMWPE/FNSI ${ }^{x} y$ fiber specimens used in the drawing experiments were cut from the dried as-prepared fibers and then stretched on a Gotech tension testing machine model GT-TFS-2000 equipped with a temperature-controlled oven. The fibers are $150 \mathrm{~mm}$ in length, which were wound and clamped in a stretching device and then stretched at a crosshead speed of $20 \mathrm{~mm} / \mathrm{min}$ and a constant temperature of $95^{\circ} \mathrm{C}$. The draw ratio of each fiber specimen was determined as the ratio of the marked displacement after and before drawing. The marked displacement before drawing was $27 \mathrm{~mm}$. The tensile properties of the as-prepared and drawn fibers were determined using a Hung Ta tension testing machine model HT-9112 at a crosshead speed of $20 \mathrm{~mm} / \mathrm{min}$. A minimum of five samples of each specimen were tested and averaged during the tensile experiments.

\section{Results and Discussion}

3.1. Fourier Transform Infrared Spectroscopy. Figure 1 illustrates typical Fourier transform infrared (FTIR) spectra of nanosilica $\left(\mathrm{NSI}^{x}\right)$, functionalized nanosilica $\left(\mathrm{FNSI}_{\mathrm{m} y}^{x}\right)$, and maleic anhydride grafted polyethylene $\left(\mathrm{PE}_{\mathrm{g}-\mathrm{MAH}}\right)$ specimens. $\mathrm{PE}_{\mathrm{g}-\mathrm{MAH}}$ specimen exhibited two distinctive absorption bands centered at 1711 and $1791 \mathrm{~cm}^{-1}$, which were generally attributed to the motion of $\mathrm{O}-\mathrm{C}=\mathrm{O}$ and $\mathrm{C}=\mathrm{O}$ stretching vibrations of maleic anhydride [31] (see Figure 1(a)). As shown in Figures 1(b), 1(f), and 1(j), there are three distinguished absorption bands centered at 1097, 1635, and $3442 \mathrm{~cm}^{-1}$ corresponding to the motions of Si-O-Si stretching, $\mathrm{H}-\mathrm{O}-\mathrm{H}$ bending, and $\mathrm{Si}-\mathrm{OH}$ stretching vibrations [31], respectively, which were found in the spectra of $\mathrm{NSI}^{100}, \mathrm{NSI}^{300}$, and NSI ${ }^{600}$ specimens. It is interesting to note that the peak magnitudes of Si-O-Si stretching, $\mathrm{H}-\mathrm{O}-\mathrm{H}$ bending, and $\mathrm{Si}-\mathrm{OH}$ stretching bands of $\mathrm{NSI}^{x}$ specimens increased significantly as their quoted specific surface areas increased from 100 to 300 and $600 \mathrm{~m}^{2} / \mathrm{g}$ (see Figures 1(b), 1(f), and 1(j)). The significant increase in the magnitude of $\mathrm{Si}-\mathrm{O}-\mathrm{Si}$ stretching, $\mathrm{H}-\mathrm{O}-\mathrm{H}$ bending, and $\mathrm{Si}-\mathrm{OH}$ stretching bands of $\mathrm{NSI}^{x}$ specimens is attributed to the increased amounts of $\mathrm{Si}-\mathrm{O}-\mathrm{Si}, \mathrm{H}-\mathrm{O}-\mathrm{H}$, and $\mathrm{Si}-\mathrm{OH}$ groups exposed on $\mathrm{NSI}^{x}$ particles with higher specific surface areas.

After grafting $\mathrm{PE}_{\mathrm{g}-\mathrm{MAH}}$ to $\mathrm{NSI}^{100}, \mathrm{NSI}^{300}$, and $\mathrm{NSI}^{600}$ particles, the peak magnitudes corresponding to $\mathrm{H}-\mathrm{O}-\mathrm{H}$ bending and $\mathrm{Si}-\mathrm{OH}$ stretching bands of $\mathrm{FNSI}^{x}{ }_{\mathrm{m} y}$ specimens reduced significantly as the weight ratios of $\mathrm{PE}_{\mathrm{g}-\mathrm{MAH}}$ to $\mathrm{NSI}^{x}$ increased (see Figures $1(\mathrm{~b})$ to $1(\mathrm{e}), 1(\mathrm{f})$ to $1(\mathrm{i})$, and $1(\mathrm{j})$ to $1(\mathrm{~m})$ ). In fact, as shown in Figures $1(\mathrm{~d})$ to $1(\mathrm{e}), 1(\mathrm{~h})$ to $1(\mathrm{i})$, and 1(l) to $1(\mathrm{~m}), \mathrm{H}-\mathrm{O}-\mathrm{H}$ bending and $\mathrm{Si}-\mathrm{OH}$ stretching bands originally present in $\mathrm{NSI}^{x}$ specimens disappeared almost completely as the weight ratios of $\mathrm{PE}_{\mathrm{g}-\mathrm{MAH}}$ to $\mathrm{NSI}^{100}, \mathrm{NSI}^{300}$, and $\mathrm{NSI}^{600}$ of $\mathrm{FNSI}_{\mathrm{m} y}^{100}, \mathrm{FNSI}_{\mathrm{m} y}^{300}$, and $\mathrm{FNSI}^{600}{ }_{\mathrm{m} y}$ specimens were equal to or more than 3,6 , and 9 , respectively. In the meantime, a new absorption band centered at around $1228 \mathrm{~cm}^{-1}$ corresponding to the motion of ester $\mathrm{C}-\mathrm{O}$ stretching vibration [31] was found in the spectra of $\mathrm{FNSI}_{\mathrm{m} y}^{100}, \mathrm{FNSI}_{\mathrm{m} y}^{300}$, and $\mathrm{FNSI}^{600}{ }_{\mathrm{m} y}$ specimens (see Figures $1(\mathrm{c})$ to $1(\mathrm{e}), 1(\mathrm{~g})$ to $1(\mathrm{i})$, and $1(\mathrm{k})$ to $1(\mathrm{~m})$ ). In contrast, the absorption bands centered at 1711 and $1791 \mathrm{~cm}^{-1}$ corresponding to the motion of $\mathrm{C}=\mathrm{O}$ and $\mathrm{O}-\mathrm{C}=\mathrm{O}$ stretching vibrations of maleic anhydride gradually reappeared as the weight ratios of $\mathrm{PE}_{\mathrm{g}-\mathrm{MAH}}$ to $\mathrm{NSI}^{100}, \mathrm{NSI}^{300}$, and $\mathrm{NSI}^{600}$ of $\mathrm{FNSI}_{\mathrm{m} y}^{100}, \mathrm{FNSI}_{\mathrm{m} y}^{300}$, and FNSI $_{\mathrm{m} y}^{600}$ specimens, respectively, were equal to 6,9 , and 12. Presumably, the gradually disappearing $\mathrm{H}-\mathrm{O}-\mathrm{H}$ bending and $\mathrm{Si}-\mathrm{OH}$ stretching bands and newly developed ester $\mathrm{C}-\mathrm{O}$ stretching bands of $\mathrm{FNSI}_{\mathrm{m} y}^{100}, \mathrm{FNSI}_{\mathrm{m} y}^{300}$, and $\mathrm{FNSI}_{\mathrm{m} y}^{600}$ specimens are attributed to the reaction of the hydroxyl groups of $\mathrm{NSI}^{100}, \mathrm{NSI}^{300}$, and $\mathrm{NSI}^{600}$ particles with the maleic anhydride groups of $\mathrm{PE}_{\mathrm{g}-\mathrm{MAH}}$ molecules during their functionalized processes. The reappearance of $\mathrm{O}-\mathrm{C}=\mathrm{O}$ and $\mathrm{C}=\mathrm{O}$ stretching bands of maleic anhydride groups is most likely due to the overdosage of $\mathrm{PE}_{\mathrm{g}-\mathrm{MAH}}$ during the functionalized processes of $\mathrm{FNSI}_{\mathrm{m} y}^{100}$, $\mathrm{FNSI}_{\mathrm{m} y}^{300}$, and $\mathrm{FNSI}_{\mathrm{m} y}^{600}$ particles.

3.2. Morphological Analyses of $\mathrm{NSI}^{x}$ and $\mathrm{FNSI}_{\mathrm{m} y}^{x}$ Particles. Figure 2 exhibits typical TEM micrographs of $\mathrm{NSI}^{x}$ and $\mathrm{FNSI}_{\mathrm{m} y}^{x}$ particles. Typical irregular particle feature with dimensions of 250-350, 150-200, and 50-80 nm in diameter was observed for $\mathrm{NSI}^{100}, \mathrm{NSI}^{300}$, and $\mathrm{NSI}^{600}$ particles (see Figures 2(a), 2(d), and 2(g)). After modification by $\mathrm{PE}_{\mathrm{g}-\mathrm{MAH}}$, some translucent resins were found attaching on the surfaces of $\mathrm{NSI}^{100}$, $\mathrm{NSI}^{300}$, and NSI ${ }^{600}$ particles, wherein the amounts of attached translucent resins increased gradually as the weight ratios of $\mathrm{PE}_{\mathrm{g}-\mathrm{MAH}}$ to $\mathrm{NSI}^{100}, \mathrm{NSI}^{300}$, and $\mathrm{NSI}^{600}$ increased, respectively (see Figures 2(b) to 2(c), 2(e) to 2(g), and $2(\mathrm{~h})$ to $2(\mathrm{i})$ ). As evidenced by FTIR analyses in the previous section, the attached translucent resins were most likely the grafted $\mathrm{PE}_{\mathrm{g}-\mathrm{MAH}}$ molecules, which were firmly bonded to $\mathrm{NSI}^{100}, \mathrm{NSI}^{300}$, and $\mathrm{NSI}^{600}$ particles by the reaction of the maleic anhydride groups of $\mathrm{PE}_{\mathrm{g}-\mathrm{MAH}}$ resins with the hydroxyl groups of $\mathrm{NSI}^{100}{ }^{2} \mathrm{NSI}^{300}$, and $\mathrm{NSI}^{600}$ particles, respectively. In fact, the translucent resins were found fully surrounding and overwrapping on $\mathrm{NSI}^{100}, \mathrm{NSI}^{300}$, and $\mathrm{NSI}^{600}$ particles, as the weight ratios of $\mathrm{PE}_{\mathrm{g}-\mathrm{MAH}}$ to $\mathrm{NSI}^{100}, \mathrm{NSI}^{300}$, and $\mathrm{NSI}^{600}$ were greater than 3,6 , and 12, respectively (see Figures 2(c), 2(f), and 2(i)).

3.3. Specific Surface Area Analyses of $N S I^{x}$ and $\mathrm{FNSI}_{\mathrm{m} y}{ }_{\mathrm{y}}$ Particles. The values of specific surface areas of $\mathrm{NSI}^{x}$ and $\mathrm{FNSI}^{x}{ }_{\mathrm{m} y}$ particles are summarized in Figure 3 and Table 1. The specific 

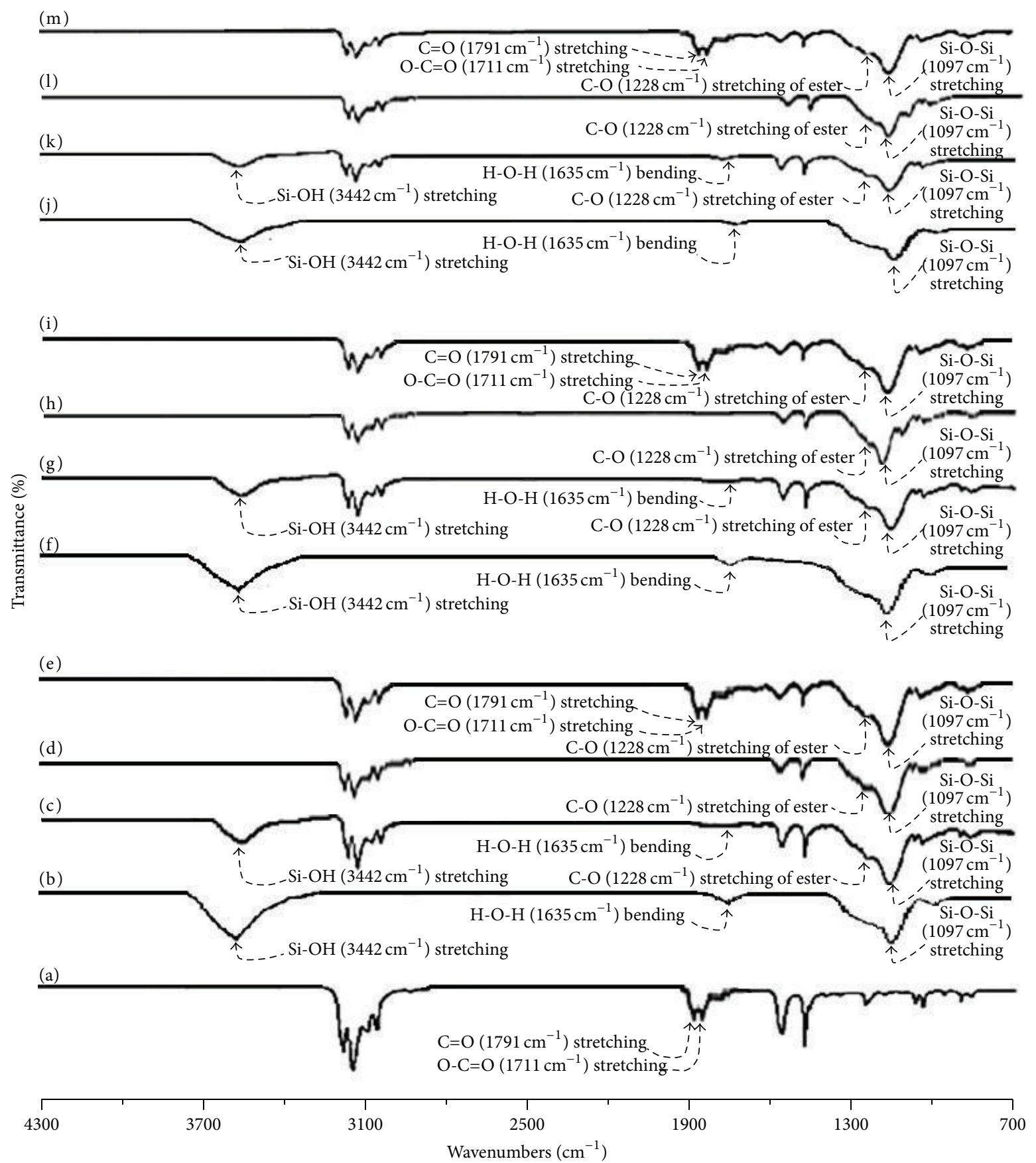

Figure 1: FTIR spectra of (a) $\mathrm{PE}_{\mathrm{g}-\mathrm{MAH}}$, (b) $\mathrm{NSI}^{600}$, (c) $\mathrm{FNSI}^{600}{ }_{\mathrm{m} 3}$, (d) $\mathrm{FNSI}^{600}{ }_{\mathrm{m} 9}$, (e) $\mathrm{FNSI}^{600}{ }_{\mathrm{m} 12}$, (f) $\mathrm{NSI}^{300}$, (g) $\mathrm{FNSI}^{300}{ }_{\mathrm{m} 3}$, (h) FNSI ${ }^{300}{ }_{\mathrm{m} 6}$, (i) $\mathrm{FNSI}^{300}{ }_{\mathrm{m} 9}$, (j) $\mathrm{NSI}^{100}$, (k) FNSI ${ }_{\mathrm{m} 2}^{100}$, (l) FNSI ${ }_{\mathrm{m} 3}^{100}$, and (m) FNSI ${ }^{100}{ }_{\mathrm{m} 6}$ specimens (the superscript $x$ denotes the quoted specific surface areas of virgin NSI ${ }^{x}$ nanosilica particles; $y$ denotes the weight ratio of $\mathrm{PE}_{\mathrm{g}-\mathrm{MAH}}$ to $\mathrm{NSI}^{x}$ used in the preparation processes of FNSI ${ }_{\mathrm{m} y}$ functionalized nanosilica particles).

surface areas of $\mathrm{NSI}^{100}, \mathrm{NSI}^{300}$, and $\mathrm{NSI}^{600}$ particles were evaluated at around 100, 300, and $600 \mathrm{~m}^{2} / \mathrm{g}$ (i.e., 102.3, 303.9, and $601.7 \mathrm{~m}^{2} / \mathrm{g}$ ), respectively. After modification by $\mathrm{PE}_{\mathrm{g}-\mathrm{MAH}}$, the specific surface areas of $\mathrm{FNSI}_{\mathrm{m} y}^{100}, \mathrm{FNSI}_{\mathrm{m} y}^{300}$, and FNSI $^{600}{ }_{\mathrm{m} y}$ particles reached a maximal value at 129.8, 335.8, and $630.7 \mathrm{~m}^{2} / \mathrm{g}$, respectively, as the weight ratios of $\mathrm{PE}_{\mathrm{g}-\mathrm{MAH}}$ to $\mathrm{NSI}^{100}, \mathrm{NSI}^{300}$, and NSI ${ }^{600}$ approached an optimal value at 3, 6, and 9, respectively. Presumably, the beneficial effect of $\mathrm{PE}_{\mathrm{g}-\mathrm{MAH}}$ contents on specific surface areas of $\mathrm{FNSI}^{x}{ }_{\mathrm{m} y}$ particles is attributed to the increase in grafted amounts and specific surface areas of $\mathrm{PE}_{\mathrm{g}-\mathrm{MAH}}$ on $\mathrm{NSI}^{x}$ particles during their functionalized processes. However, $\mathrm{PE}_{\mathrm{g}-\mathrm{MAH}}$ molecules may agglomerate, bundle, entangle together, and overwrap $\mathrm{NSI}^{x}$ 


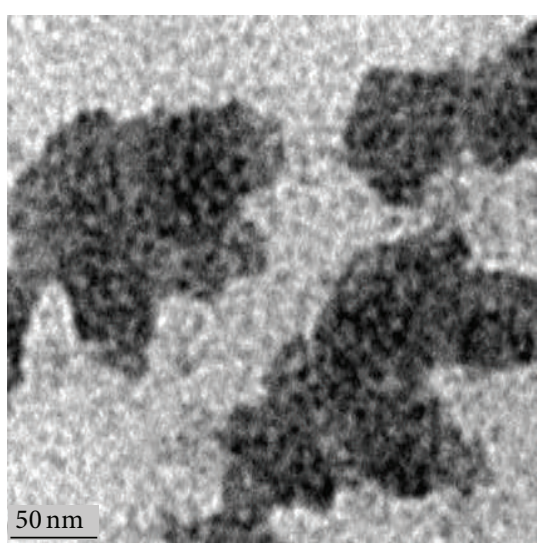

(a)

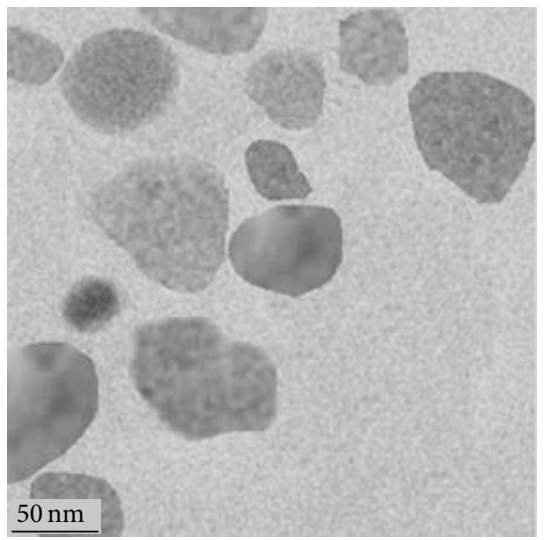

(d)

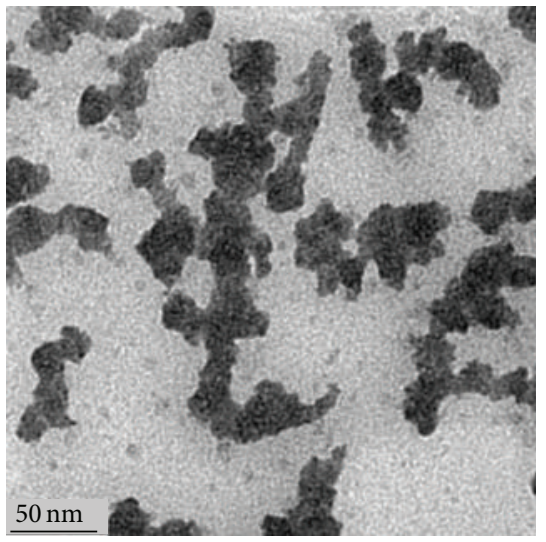

(g)

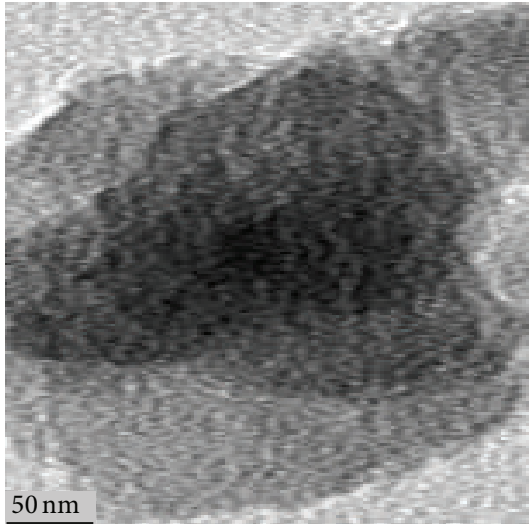

(b)

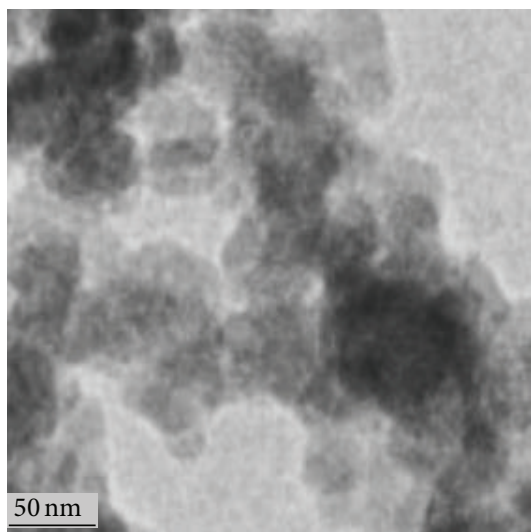

(e)

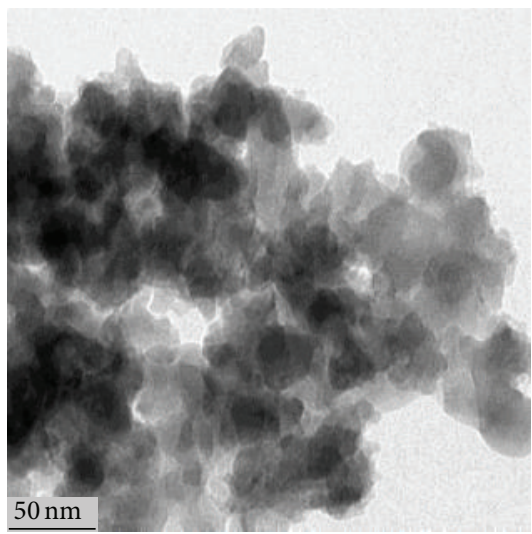

(h)

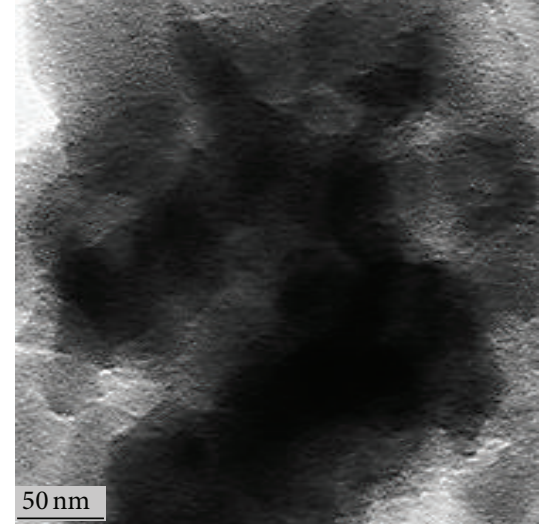

(c)

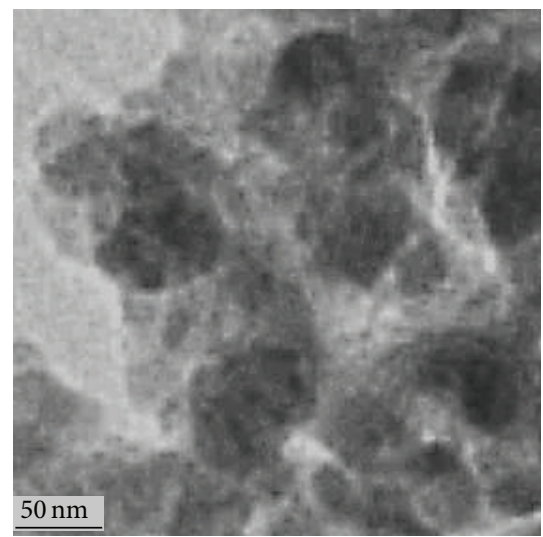

(f)

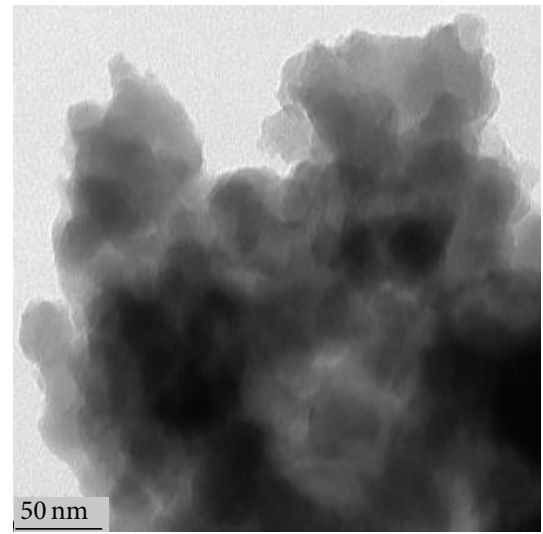

(i)

FIGURE 2: TEM micrographs of (a) $\mathrm{NSI}^{100}$, (b) $\mathrm{FNSI}^{100}{ }_{\mathrm{m} 3}$, (c) $\mathrm{FNSI}^{100}$ and (i) FNSI ${ }_{\mathrm{m} 12}^{600}$ specimens.

particles, as $\mathrm{PE}_{\mathrm{g}-\mathrm{MAH}}$ molecules are superfluous and can no longer graft onto $\mathrm{NSI}^{x}$ particles. As evidenced by morphology analyses in the previous section, some translucent resins were found fully surrounding and overwrapping on $\mathrm{NSI}^{x}$ particles (see Figures 2(c), 2(g), and 2(i)), as the weight ratios of $\mathrm{PE}_{\mathrm{g}-\mathrm{MAH}}$ to $\mathrm{NSI}^{100}, \mathrm{NSI}^{300}$, and $\mathrm{NSI}^{600}$ were more than 3,6 , and 9, respectively. Based on this premise, it is reasonable to infer that the overwrapped $\mathrm{FNSI}^{x}{ }_{\mathrm{m} y}$ particles exhibit relatively lower specific surface areas than those FNSI $^{100}{ }_{\mathrm{m} 3}, \mathrm{FNSI}^{300}{ }_{\mathrm{m} 6}$, and $\mathrm{FNSI}^{600}{ }_{\mathrm{m} 9}$ particles grafted with proper amounts of $\mathrm{PE}_{\mathrm{g}-\mathrm{MAH}}$ resins.

3.4. Thermal Properties of the As-Prepared Fibers. Typical DSC thermograms, melting temperature $\left(T_{m}\right)$, percentage crystallinity $\left(X_{c}\right)$, and evaluated lamellar thickness $\left(l_{c}\right)$ values of UHMWPE $\left(\mathrm{F}_{100}\right)$, UHMWPE/NSI $\left(\mathrm{F}_{100} \mathrm{NSI}_{z}{ }_{z}\right)$, 


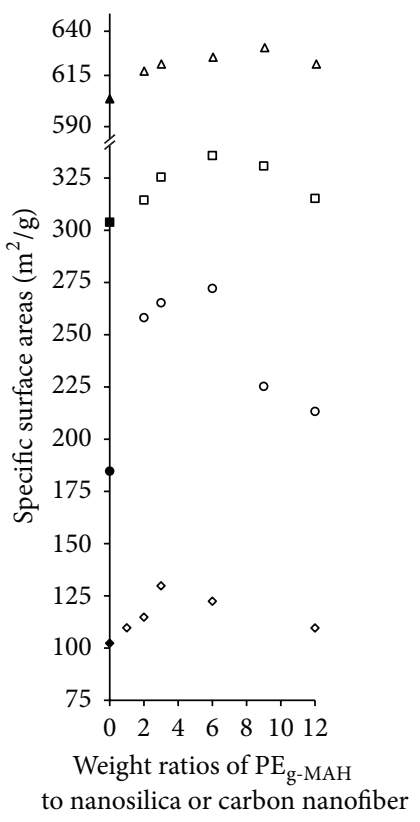

FIGURE 3: Specific surface areas of carbon nanofiber $(\bullet)$, NSI $^{100}(\bullet)$, $\mathrm{NSI}^{300}(\boldsymbol{\square}), \operatorname{NSI}^{600}(\boldsymbol{\Delta}), \mathrm{FNSI}^{100}{ }_{\mathrm{m} y}(\diamond), \mathrm{FNSI}^{300}{ }_{\mathrm{m} y}(\square), \mathrm{FNSI}_{\mathrm{m} y}^{600}(\triangle)$, and modified carbon nanofiber $(\circ)$ specimens.

and UHMWPE/FNSI $\left(\mathrm{F}_{100} \mathrm{FNSI}_{\mathrm{m} y-z}\right)$ as-prepared fiber series specimens are summarized in Figure 4 and Table 2. A main melting endotherm with $T_{m}$ and $X_{c}$ at $142.7^{\circ} \mathrm{C}$ and $65.1 \%$, respectively, was found for $\mathrm{F}_{100}$ specimen. After incorporation of $\mathrm{NSI}^{x}$ and/or $\mathrm{FNSI}_{\mathrm{m} y}^{x}$ particles in UHMWPE, $T_{m}$ (or evaluated $l_{c}$ ) values of $\mathrm{F}_{100} \mathrm{NSI}_{z}{ }_{z}$ (i.e., $\mathrm{F}_{100} \mathrm{NSI}_{z}^{100}, \mathrm{~F}_{100} \mathrm{NSI}^{300}$, and $\mathrm{F}_{100} \mathrm{NSI}_{z}^{600}$ ) and/or $\mathrm{F}_{100}$ FNSI $_{\mathrm{m} y-z}$ (i.e., $\mathrm{F}_{100} \mathrm{FNSI}_{\mathrm{m} y-z}, \mathrm{~F}_{100} \mathrm{FNSI}_{\mathrm{m} y-z}^{300}$, and $\mathrm{F}_{100} \mathrm{FNSI}^{600}{ }_{\mathrm{m} y-z}$ ) as-prepared fibers reduced to a minimal value, as their $\mathrm{NSI}^{x}$ and/or $\mathrm{FNSI}^{x}{ }_{\mathrm{m} y}$ contents reached an optimal value, respectively, in which $T_{m}$ and $l_{c}$ values of $\mathrm{F}_{100} \mathrm{FNSI}_{\mathrm{m} y \text {-0.075 }}{ }^{100} \quad \mathrm{~F}_{100} \mathrm{FNSI}_{\mathrm{m} y-0.05}^{300}$, and $\mathrm{F}_{100} \mathrm{FNSI}_{\mathrm{m} y-0.0375}^{600}$ as-prepared fibers prepared at the optimal $\mathrm{FNSI}^{x}{ }_{\mathrm{m} y}$ contents at $0.075,0.05$, and $0.0375 \mathrm{phr}$, respectively, were significantly lower than those of the corresponding $\mathrm{F}_{100} \mathrm{NSI}^{100}{ }_{0.1}, \mathrm{~F}_{100} \mathrm{NSI}^{300}{ }_{0.0625}$, and $\mathrm{F}_{100} \mathrm{NSI}^{600}{ }_{0.05}$ as-prepared fibers with an optimal $\mathrm{NSI}^{x}$ content at $0.1,0.0625$, and 0.05 phr, respectively. However, $X_{c}$ values of $\mathrm{F}_{100} \mathrm{NSI}_{z}^{x}$ and/or $\mathrm{F}_{100} \mathrm{FNSI}^{x}{ }_{\mathrm{m} y-z}$ as-prepared fibers increased to a maximal value, as $\mathrm{NSI}^{x}$ and/or $\mathrm{FNSI}^{x}{ }_{\mathrm{m} y}$ contents reached their corresponding optimal values, respectively, wherein $X_{c}$ values of $\mathrm{F}_{100} \mathrm{FNSI}^{100}{ }_{\mathrm{m} y-0.075}$, $\mathrm{F}_{100} \mathrm{FNSI}_{\mathrm{m} y-0.05}^{300}$, and $\mathrm{F}_{100} \mathrm{FNSI}_{\mathrm{m} y-0.0375}^{600}$ as-prepared fibers prepared at their optimal $\mathrm{FNSI}^{x}{ }_{\mathrm{m} y}$ contents, respectively, were significantly higher than those of the corresponding $\mathrm{F}_{100} \mathrm{NSI}^{100}{ }_{0.1}, \quad \mathrm{~F}_{100} \mathrm{NSI}^{300}{ }_{0.0625}$, and $\mathrm{F}_{100} \mathrm{NSI}_{0.05}^{600}$ as-prepared fibers prepared at their optimal NSI ${ }^{x}$ contents, respectively. Moreover, it is worth noting that $\mathrm{F}_{100} \mathrm{FNSI}_{\mathrm{m} y-0.075}, \mathrm{~F}_{100} \mathrm{FNSI}_{\mathrm{m} y-0.05}^{300}$, and
$\mathrm{F}_{100} \mathrm{FNSI}^{600} \mathrm{~m} y-0.0375$ as-prepared fibers prepared at the optimal FNSI ${ }_{\mathrm{m} y}^{x}$ contents exhibited another minimal $T_{m}$ (or evaluated $l_{c}$ ) but other maximal $X_{c}$ values as their FNSI $^{100}{ }_{\mathrm{m} y}$, $\mathrm{FNSI}_{\mathrm{m} y}^{300}$, and $\mathrm{FNSI}_{\mathrm{m} y}^{600}$ were modified using an optimal weight ratio of $\mathrm{PE}_{\mathrm{g}-\mathrm{MAH}}$ to $\mathrm{NSI}^{100}, \mathrm{NSI}^{300}$, and $\mathrm{NSI}^{600}$ at 3, 6, and 9, respectively (see Figures 5(j), 6(i), and 7(h)). Finally, it is interesting to note that the lowest $T_{m}$ (or evaluated $l_{c}$ ) values obtained for $\mathrm{F}_{100} \mathrm{FNSI}^{100}{ }_{\mathrm{m} 3-0.075}, \mathrm{~F}_{100} \mathrm{FNSI}^{300}{ }_{\text {m6-0.05 }}$, and $\mathrm{F}_{100} \mathrm{FNSI}^{600}{ }_{\mathrm{m} 9-0.0375}$ as-prepared fibers prepared at the optimal $\mathrm{FNSI}^{x}{ }_{\mathrm{m} y}$ contents and weight ratio of $\mathrm{PE}_{\mathrm{g}-\mathrm{MAH}}$ to $\mathrm{NSI}^{x}$ reduced significantly as the specific surface areas of FNSI $^{x}{ }_{\mathrm{m} y}$ particles increased, while the highest $X_{c}$ values obtained for $\mathrm{F}_{100} \mathrm{FNSI}_{\mathrm{m} 3-0.075}{ }^{100} \mathrm{~F}_{100} \mathrm{FNSI}^{300}{ }_{\mathrm{m} 6-0.05}$, and $\mathrm{F}_{100} \mathrm{FNSI}^{600}{ }_{\mathrm{m} 9-0.0375}$ as-prepared fibers increased consistently as the specific surface areas of their $\mathrm{FNSI}_{\mathrm{m} y}{ }_{\mathrm{m}}$ particles increased. For instance, $T_{m}$ values of $\mathrm{F}_{100} \mathrm{FNSI}^{100}{ }_{\mathrm{m} 3-0.075}$, $\mathrm{F}_{100} \mathrm{FNSI}^{300}$ m6-0.05, and $\mathrm{F}_{100} \mathrm{FNSI}^{600}{ }_{\mathrm{m} 9-0.0375}$ as-prepared fibers reduced from $138.3^{\circ} \mathrm{C}$ to $137.6^{\circ} \mathrm{C}$ and to $136.1^{\circ} \mathrm{C}$, as the specific surface areas of $\mathrm{FNSI}^{100}{ }_{\mathrm{m} 3}, \mathrm{FNSI}^{300}{ }_{\mathrm{m} 6}$, and FNSI $^{600}{ }_{\mathrm{m} 9}$ present in $\mathrm{F}_{100} \mathrm{FNSI}_{\mathrm{m} 3-0.075}, \mathrm{~F}_{100} \mathrm{FNSI}_{\mathrm{m} 6-0.05}^{300}$, and $\mathrm{F}_{100} \mathrm{FNSI}_{\mathrm{m} 9-0.0375}$ as-prepared fibers increased from 129.8 to 335.8 and $630.7 \mathrm{~m}^{2} / \mathrm{g}$, respectively, while their $X_{c}$ values increased from $75.4 \%$ to $76.0 \%$ and $76.8 \%$, as the specific surface areas of $\mathrm{FNSI}^{100}{ }_{\mathrm{m} 3}, \mathrm{FNSI}^{300}{ }_{\mathrm{m} 6}$, and FNSI $^{600}{ }_{\mathrm{m} 9}$ present in $\mathrm{F}_{100} \mathrm{FNSI}_{\mathrm{m} 3-0.075}, \mathrm{~F}_{100} \mathrm{FNSI}_{\mathrm{m} 6-0.05}^{300}$, and $\mathrm{F}_{100} \mathrm{FNSI}^{600}{ }_{\mathrm{m} 9-0.0375}$ as-prepared fibers increased from 129.8 to 335.8 and $630.7 \mathrm{~m}^{2} / \mathrm{g}$, respectively.

As evidenced by specific surface area and TEM analyses in the previous sections, $\mathrm{NSI}^{x}$ and/or $\mathrm{FNSI}^{x}{ }_{\mathrm{m} y}$ particles are with a wide range of relatively large surface areas per volume, which make them in close proximity to a large fraction of the UHMWPE matrix. Apparently, even very small contents of dispersed $\mathrm{NSI}^{x}$ and/or $\mathrm{FNSI}^{x}$ my particles can serve as efficient nucleation sites for UHMWPE molecules during their gel spinning processes. These efficient nucleation sites of $\mathrm{NSI}^{x}$ and/or $\mathrm{FNSI}^{x}$ m $y$ particles then facilitate the crystallization of UHMWPE molecules into crystals with thinner lamellar thickness and/or lower $T_{m}$ values during their crystallization processes. After grafting $\mathrm{PE}_{\mathrm{g}-\mathrm{MAH}}$ to $\mathrm{NSI}^{100}, \mathrm{NSI}^{300}$, and $\mathrm{NSI}^{600}$ particles, the properly modified FNSI $^{x}{ }_{m} y$ particles with even higher specific surface areas are likely to disperse better in UHMWPE and serve as more effective sites for nucleation of UHMWPE molecules during their gel spinning processes than $\mathrm{NSI}^{x}$ particles. As a consequence, $\mathrm{F}_{100} \mathrm{FNSI}_{\mathrm{m} y-z}, \mathrm{~F}_{100} \mathrm{FNSI}_{\mathrm{m} y-z}^{300}$, and $\mathrm{F}_{100} \mathrm{FNSI}^{600}{ }_{\mathrm{m} y-z}$ as-prepared fiber specimens exhibit significantly higher $X_{c}$ but lower $T_{m}$ (or evaluated $l_{c}$ ) values than the corresponding $\mathrm{F}_{100} \mathrm{NSI}^{100}, \mathrm{~F}_{100} \mathrm{NSI}^{300}$, and $\mathrm{F}_{100} \mathrm{NSI}^{600}{ }_{z}$ as-prepared fiber specimens prepared with the same $\mathrm{NSI}^{x}$ contents but without modification by $\mathrm{PE}_{\mathrm{g}-\mathrm{MAH}}$, respectively. Moreover, the minimal $T_{m}$ (or evaluated $l_{c}$ ) values obtained for $\mathrm{F}_{100} \mathrm{FNSI}^{100}{ }_{\mathrm{m} 3-0.075}, \mathrm{~F}_{100} \mathrm{FNSI}^{300}{ }_{\mathrm{m} 6-0.05}$, and $\mathrm{F}_{100} \mathrm{FNSI}^{600} \mathrm{~m} 9-0.0375$ as-prepared fibers prepared at the optimal $\mathrm{FNSI}^{x}{ }_{\mathrm{m} y}$ contents and weight ratio of $\mathrm{PE}_{\mathrm{g}-\mathrm{MAH}}$ to $\mathrm{NSI}^{x}$, respectively, reduced significantly as the specific surface 


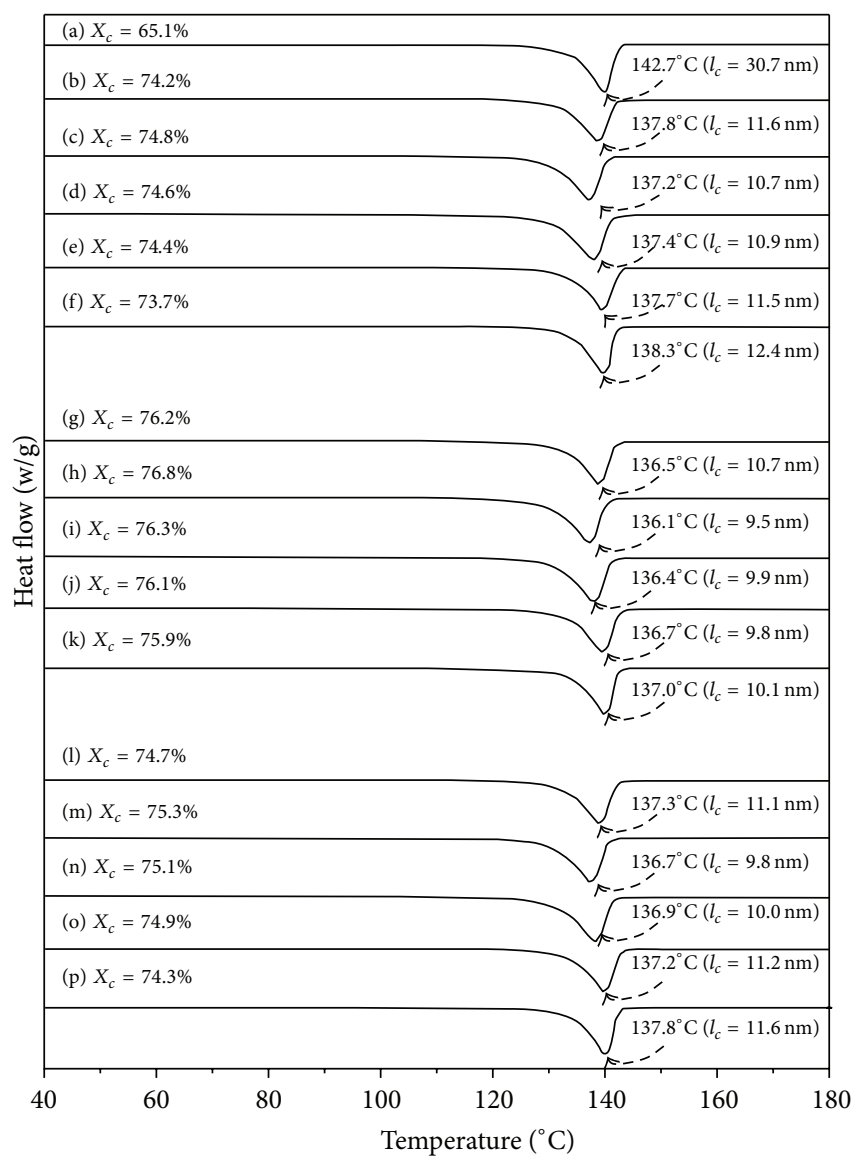

Figure 4: DSC thermograms of (a) $\mathrm{F}_{100}$, (b) $\mathrm{F}_{100} \mathrm{FNSI}^{600}$ $\mathrm{F}_{100} \mathrm{FNSI}^{600}{ }_{\mathrm{m} 3-0.075}$, (g) $\mathrm{F}_{100} \mathrm{FNSI}^{600}{ }_{\mathrm{m} 9-0.025}$, (h) $\mathrm{F}_{100} \mathrm{FNSI}^{60}$ $\mathrm{F}_{100} \mathrm{FNSI}^{600}{ }_{\mathrm{m} 12-0.025}^{\mathrm{m} 3-0.075},(\mathrm{~m}) \mathrm{F}_{100} \mathrm{FNSI}_{\mathrm{ml2}-0.0375}$, (n) $\mathrm{F}_{100} \mathrm{FNSI}^{\mathrm{m} 9-0.025}$ m9-0.0375,

(c) $\mathrm{F}_{100} \mathrm{FNSI}^{600}$ (d) $\mathrm{F}_{100} \mathrm{FNSI}^{600}$

, (j) $\mathrm{F}_{100} \mathrm{FNSI}^{600}{ }_{\mathrm{m} 9-0.625}$,

(e) $\mathrm{F}_{100} \mathrm{FNSI}^{600}{ }_{\mathrm{m} 3-0.625}$, (f)

(k) $\mathrm{F}_{100} \mathrm{FNSI}^{600}{ }^{\mathrm{m} 3-0.625}$, (l) (o) $\mathrm{F}_{100} \mathrm{FNSI}^{600}{ }_{\mathrm{m} 12-0.0625}^{\mathrm{m}}$, and (p) $\mathrm{F}_{100} \mathrm{FNSI}^{\mathrm{m} 9-0.625}{ }_{\mathrm{ml2}-0.075}$ as-prepared fibers. areas of $\mathrm{FNSI}_{\mathrm{m} y}^{x}$ particles increased, while the highest $X_{c}$ values obtained for $\mathrm{F}_{100} \mathrm{FNSI}^{100} \mathrm{~m} 3-0.075, \mathrm{~F}_{100} \mathrm{FNSI}_{\mathrm{m} 6-0.05}^{300}$, and $\mathrm{F}_{100} \mathrm{FNSI}^{600}$ m9-0.0375 as-prepared fibers increased consistently as the specific surface areas of their $\mathrm{FNSI}^{x}{ }_{\mathrm{m} y}$ particles increased.

3.5. Achievable Draw Ratios of the As-Prepared Fibers. Figure 5 summarized the achievable draw ratio (achievable

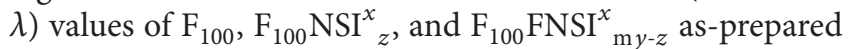
fiber specimens prepared at varying $\mathrm{NSI}^{x}$ and/or $\mathrm{FNSI}^{x}{ }_{\mathrm{m} y}$ contents, respectively. For comparison purposes, achievable $\lambda$ values of the best prepared UHMWPE/functionalized carbon nanotube (FCNT) as-prepared fibers (i.e., $\mathrm{F}_{100} \mathrm{C}_{\mathrm{f} 2-0.1}$ specimens) obtained in our previous investigations [24] were also summarized in Figure 5, in which, functionalized carbon nanotubes are with relatively high (i.e., $272.7 \mathrm{~m}^{2} / \mathrm{g}$ ) but significantly lower specific surface areas than those of $\mathrm{FNSI}_{\mathrm{m} y}^{300}$ and $\mathrm{FNSI}_{\mathrm{m} y}^{600}$ particles prepared in this study. After addition with $\mathrm{NSI}^{x}$ and/or $\mathrm{FNSI}^{x}{ }_{\mathrm{m} y}$ particles in UHMWPE, the achievable $\lambda$ values of $\mathrm{F}_{100} \mathrm{NSI}^{x}{ }_{z}$ and/or $\mathrm{F}_{100} \mathrm{FNSI}_{\mathrm{m} y-z}^{x}$ as-prepared fibers increased initially and reached a maximal value as their $\mathrm{NSI}^{x}$ and/or $\mathrm{FNSI}^{x}{ }_{\mathrm{m} y}$ contents approached an optimal value, respectively, in which the achievable $\lambda$ values of $\mathrm{F}_{100} \mathrm{FNSI}^{100}{ }_{\mathrm{m} y-0.075}, \mathrm{~F}_{100} \mathrm{FNSI}_{\mathrm{m} y-0.05}^{300}$, and $\mathrm{F}_{100} \mathrm{FNSI}^{600}{ }_{\mathrm{m} y-0.0375}$ as-prepared fibers prepared at the optimal $\mathrm{FNSI}_{\mathrm{m} y}^{x}$ contents at $0.075,0.05$, and $0.0375 \mathrm{phr}$, respectively, were significantly higher than those of the corresponding $\mathrm{F}_{100} \mathrm{NSI}^{100}{ }_{0.1}, \mathrm{~F}_{100} \mathrm{NSI}^{300}{ }_{0.0625}$, and $\mathrm{F}_{100} \mathrm{NSI}^{600}{ }_{0.05}$ as-prepared fibers prepared at the optimal $\mathrm{NSI}^{x}$ contents at $0.1,0.0625$, and $0.05 \mathrm{phr}$, respectively. Moreover, it is worth noting that $\mathrm{F}_{100} \mathrm{FNSI}_{\mathrm{m} y-0.075}^{100}, \mathrm{~F}_{100} \mathrm{FNSI}_{\mathrm{m} y-0.05}^{300}$, and $\mathrm{F}_{100} \mathrm{FNSI}^{600} \mathrm{~m} y$-0.0375 as-prepared fibers prepared at the optimal FNSI ${ }^{x} y$ contents exhibited other maximal achievable $\lambda$ values at 176, 289, and 361, respectively, as their FNSI $^{100}{ }_{\mathrm{m} y}$, $\mathrm{FNSI}_{\mathrm{m} y}^{300}$, and $\mathrm{FNSI}_{\mathrm{m} y}^{600}$ particles were modified using an optimal weight ratio of $\mathrm{PE}_{\mathrm{g}-\mathrm{MAH}}$ to $\mathrm{NSI}^{100}, \mathrm{NSI}^{300}$, and $\mathrm{NSI}^{600}$ at 3, 6, and 9, respectively. It is further interesting to note that the highest achievable $\lambda$ values obtained for the best prepared $\mathrm{F}_{100} \mathrm{FNSI}^{100}{ }_{\mathrm{m} 3-0.075}, \mathrm{~F}_{100} \mathrm{FNSI}^{300}$ m6-0.05, and $\mathrm{F}_{100} \mathrm{FNSI}^{600}{ }_{\mathrm{m} 9-0.0375}$ as-prepared fibers prepared at the optimal $\mathrm{FNSI}^{x}{ }_{\mathrm{m} y}$ contents and weight ratios of $\mathrm{PE}_{\mathrm{g}-\mathrm{MAH}}$ to $\mathrm{NSI}^{x}$ improved significantly as the specific surface areas of their $\mathrm{FNSI}^{x}{ }_{\mathrm{m} y}$ particles increased. In fact, the maximal achievable $\lambda$ value (i.e., 361) obtained for $\mathrm{F}_{100} \mathrm{FNSI}^{600}{ }_{\mathrm{m} 9-0.0375}$ 


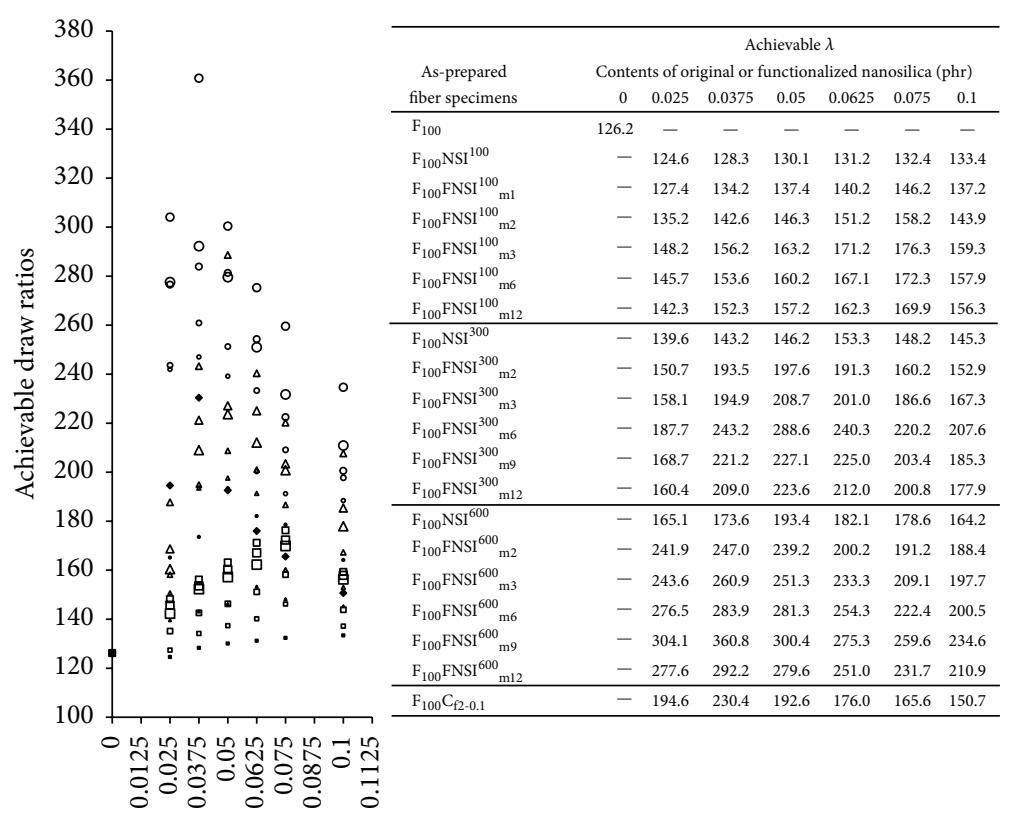

Original or functionalized nanosilica contents (phr)

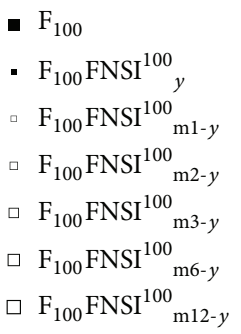

$$
\begin{aligned}
& \text { - } \mathrm{F}_{100} \mathrm{FNSI}^{300}{ }^{3} \quad \mathrm{~F}_{100} \mathrm{FNSI}_{\mathrm{m} 2-y}^{600} \\
& \triangle \mathrm{F}_{100} \mathrm{FNSI}_{\mathrm{m} 2-y}^{300} \quad \circ \mathrm{F}_{100} \mathrm{FNSI}^{600}{ }_{\mathrm{m} 3-y} \\
& \Delta \mathrm{F}_{100} \mathrm{FNSI}^{300}{ }_{\mathrm{m} 3-y} \quad \circ \mathrm{F}_{100} \mathrm{FNSI}^{600}{ }_{\mathrm{m} 6-y} \\
& \Delta \mathrm{F}_{100} \mathrm{FNSI}_{\mathrm{m} 6-y}^{300} \circ \mathrm{F}_{100} \mathrm{FNSI}_{\mathrm{m} 9-y}^{600} \\
& \Delta \mathrm{F}_{100} \mathrm{FNSI}_{\mathrm{m} 9-y}^{300} \circ \mathrm{F}_{100} \mathrm{FNSI}_{\mathrm{m} 12-y}^{600} \\
& \Delta \mathrm{F}_{100} \mathrm{FNSI}^{300}{ }_{\mathrm{m} 12-y} \quad-\mathrm{F}_{100} \mathrm{C}_{\mathrm{f2}-0.1} \\
& \text { - } \mathrm{F}_{100} \mathrm{FNSI}^{600} y
\end{aligned}
$$

Figure 5: Achievable draw ratios as-prepared fibers.

as-prepared fiber is about 2.05 and 1.25 times of those of $\mathrm{F}_{100} \mathrm{FNSI}^{100}{ }_{\mathrm{m} 3-0.075}$ and the best prepared UHMWPE/FCNT as-prepared fibers and is 2.85 times of that of $\mathrm{F}_{100}$ as-prepared fiber without addition of original and/or modified nanosilica particles.

3.6. Orientation Factor Analyses of the As-Prepared and Drawn Fiber Specimens. Typical orientation factor $\left(f_{0}\right)$ values of $\mathrm{F}_{100}, \mathrm{~F}_{100} \mathrm{NSI}_{z}^{x}$, and $\mathrm{F}_{100} \mathrm{FNSI}^{x}{ }_{\mathrm{m} y-z}$ as-prepared and drawn fibers are summarized in Figure 6. No significant difference in $f_{0}$ values was found for $\mathrm{F}_{100}, \mathrm{~F}_{100} \mathrm{NSI}_{z}^{x}$, and $\mathrm{F}_{100} \mathrm{FNSI}_{\mathrm{m} y-z}^{x}$ as-prepared fibers. As expected, $f_{0}$ values of $\mathrm{F}_{100}, \mathrm{~F}_{100} \mathrm{NSI}_{z}^{x}$, and $\mathrm{F}_{100} \mathrm{FNSI}^{x}{ }_{\mathrm{m} y-z}$ fibers increased consistently as their draw ratios increased. After addition of $\mathrm{NSI}_{z}^{x}$ and/or $\mathrm{FNSI}^{x}{ }_{\mathrm{m} y-z}$ particles, $f_{0}$ values of drawn $\mathrm{F}_{100} \mathrm{NSI}_{z}^{x}$ and/or $\mathrm{F}_{100} \mathrm{FNSI}_{\mathrm{m} y-z}$ fibers were significantly higher than those of drawn $\mathrm{F}_{100}$ fibers with the same draw ratios. $f_{0}$ values of drawn $\mathrm{F}_{100} \mathrm{NSI}_{z}^{x}$ fibers with a fixed draw ratio reached a maximal value as their $\mathrm{NSI}^{100}$, $\mathrm{NSI}^{300}$, and $\mathrm{NSI}^{600}$ contents approached the optimal values at $0.1,0.0625$, and $0.05 \mathrm{phr}$, respectively. Similarly, $f_{0}$ values of each drawn $\mathrm{F}_{100} \mathrm{FNSI}_{\mathrm{m} y-z}$ fiber series specimen reached a maximal value as their $\mathrm{FNSI}_{\mathrm{m} y}^{100}, \mathrm{FNSI}_{\mathrm{m} y}^{300}$, and $\mathrm{FNSI}_{\mathrm{m} y}^{600}$ contents approached an optimal value at $0.075,0.05$, and $0.0375 \mathrm{phr}$, respectively, in which, $f_{0}$ values of drawn $\mathrm{F}_{100} \mathrm{FNSI}_{\mathrm{m} y \text {-0.075 }}, \mathrm{F}_{100} \mathrm{FNSI}_{\mathrm{m} y \text {-0.05 }}^{300}$, and $\mathrm{F}_{100} \mathrm{FNSI}_{\mathrm{m} y \text {-0.0375 fibers prepared at the optimal }}^{600}$ FNSI $^{x}{ }_{\mathrm{m} y}$ contents were significantly higher than those of the corresponding drawn $\mathrm{F}_{100} \mathrm{NSI}^{100}{ }_{0.1}, \mathrm{~F}_{100} \mathrm{NSI}^{300}{ }_{0.0625}$, and $\mathrm{F}_{100} \mathrm{NSI}_{0.05}^{600}$ fibers prepared with the same draw ratios and at an optimal $\mathrm{NSI}^{x}$ content, respectively. Moreover, it is worth noting that $\mathrm{F}_{100} \mathrm{FNSI}^{100}{ }_{\mathrm{m} y-0.075}, \mathrm{~F}_{100} \mathrm{FNSI}_{\mathrm{m} y-0.05}^{300}$, and $\mathrm{F}_{100} \mathrm{FNSI}^{600}{ }_{\mathrm{m} y-0.0375}$ drawn fibers prepared at the optimal FNSI $^{x}{ }_{\mathrm{m} y}$ contents exhibited other maximal $f_{0}$ values as their $\mathrm{FNSI}_{\mathrm{m} y}^{100}$. $\mathrm{FNSI}^{300}{ }_{\mathrm{m} y}$, and $\mathrm{FNSI}_{\mathrm{m} y}^{600}$ particles were modified using an optimal weight ratio of $\mathrm{PE}_{\mathrm{g}-\mathrm{MAH}}$ to $\mathrm{NSI}^{100}$, $\mathrm{NSI}^{300}$, and $\mathrm{NSI}^{600}$ at 3,6 , and 9 , respectively. It is further interesting to note that the maximal $f_{0}$ values obtained for the best prepared $\mathrm{F}_{100} \mathrm{FNSI}^{100}{ }_{\mathrm{m} 3-0.075}, \mathrm{~F}_{100} \mathrm{FNSI}^{300}$ m6-0.05, and $\mathrm{F}_{100} \mathrm{FNSI}^{600}$ m9-0.0375 as-prepared fibers prepared at the optimal $\mathrm{FNSI}^{x}{ }_{\mathrm{m} y}$ contents and weight ratios of $\mathrm{PE}_{\mathrm{g}-\mathrm{MAH}}$ to $\mathrm{NSI}^{x}$ improved significantly as the specific surface areas of their $\mathrm{FNSI}^{x}{ }_{\mathrm{m} y}$ particles increased.

As evidenced by thermal and lamellar thickness analyses, $T_{m}$ (or evaluated $l_{c}$ ) values of $\mathrm{F}_{100} \mathrm{NSI}_{z}{ }_{z}$ and/or 


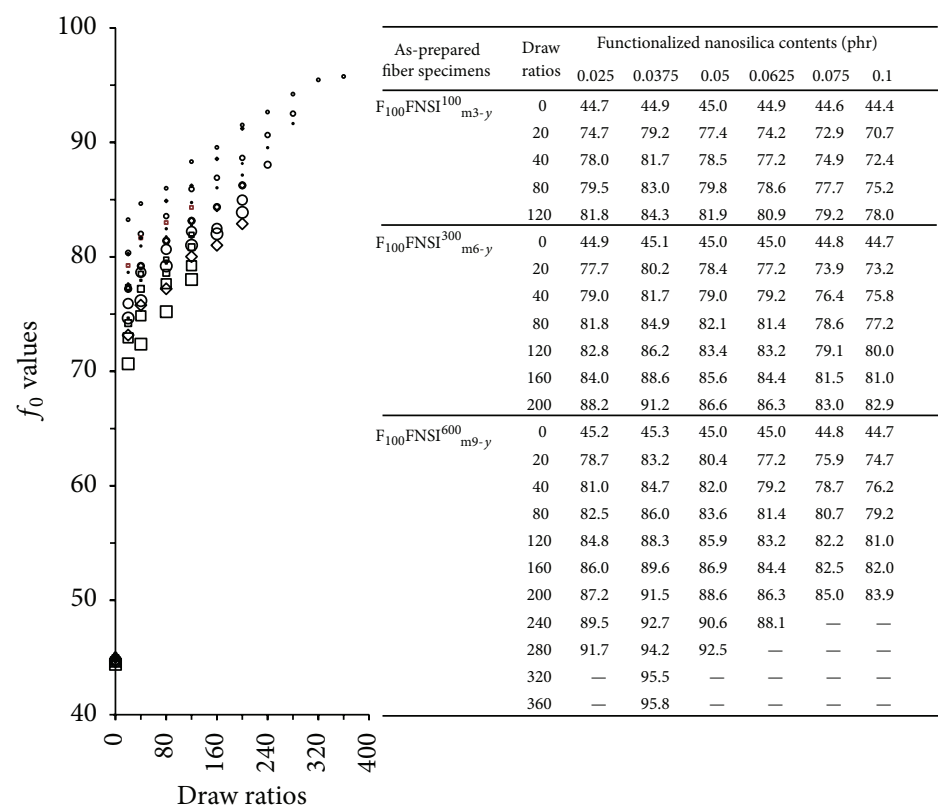

\begin{tabular}{|c|c|c|}
\hline $\begin{array}{ll} & \mathrm{F}_{100} \mathrm{FNSI}^{100}{ }^{100}{ }^{\mathrm{m} 3-0.025} \\
\square & \mathrm{F}_{100} \mathrm{FNSI}^{100}{ }^{\mathrm{m} 3-0.0375} \\
\square & \mathrm{F}_{100} \mathrm{FNSI}^{100}{ }^{\mathrm{m} 3-0.05} \\
\square & \mathrm{F}_{100} \mathrm{FNSI}^{100}{ }^{\mathrm{m}-0.0} \\
\square & \mathrm{F}_{100} \mathrm{FNSI}^{100}{ }^{\mathrm{m}-0.0625} \\
\square & \mathrm{F}_{100} \mathrm{FNSI}^{100}{ }_{\mathrm{m} 3-0.1}^{\mathrm{m}-0.075}\end{array}$ & $\begin{aligned} & \mathrm{F}_{100} \mathrm{FNSI}^{300}{ }^{\mathrm{m} 6-0.025} \\
\diamond & \mathrm{F}_{100} \mathrm{FNSI}^{300}{ }^{\mathrm{m} 6-0.0375} \\
\diamond & \mathrm{F}_{100} \mathrm{FNSI}^{300}{ }^{\mathrm{m}}{ }^{\mathrm{m} 6-0.05} \\
\diamond & \mathrm{F}_{100} \mathrm{FNSI}^{300}{ }^{\mathrm{m} 6-0.0625} \\
\diamond & \mathrm{F}_{100} \mathrm{FNSI}^{300}{ }^{\mathrm{m} 6-0.075} \\
\diamond & \mathrm{F}_{100} \mathrm{FNSI}^{300}{ }_{\mathrm{m} 6-0.1}\end{aligned}$ & 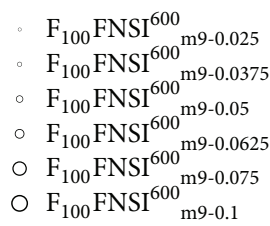 \\
\hline
\end{tabular}

Figure 6: The orientation factor $\left(f_{0}\right)$ values as-prepared and drawn fibers with varying draw ratios.

$\mathrm{F}_{100} \mathrm{FNSI}_{\mathrm{m} y-z}^{x}$ as-prepared fibers reduced to a minimal value, as their $\mathrm{NSI}^{x}$ and/or $\mathrm{FNSI}^{x}{ }_{\mathrm{m} y}$ contents reached an optimal value, respectively. Moreover, the lowest $T_{m}$ (or evaluated $l_{c}$ ) values obtained for the best prepared $\mathrm{F}_{100} \mathrm{FNSI}^{100}{ }_{\mathrm{m} 3-0.075}$, $\mathrm{F}_{100} \mathrm{FNSI}^{300}{ }_{\mathrm{m6}-0.05}$, and $\mathrm{F}_{100} \mathrm{FNSI}^{600}{ }_{\mathrm{m} 9-0.0375}$ as-prepared fibers prepared at the optimal FNSI ${ }_{\mathrm{m} y}^{x}$ contents and weight ratio of $\mathrm{PE}_{\mathrm{g}-\mathrm{MAH}}$ to $\mathrm{NSI}^{x}$ reduced significantly as the specific surface areas of their $\mathrm{FNSI}_{\mathrm{m} y}^{x}$ particles increased. Presumably, these crystals with lower $T_{m}$ and/or evaluated $l_{c}$ values can be melted and pulled out of folded lamellar crystals relatively easily during the ultradrawing processes, and hence this results in higher drawability and orientation of the best prepared $\mathrm{F}_{100} \mathrm{FNSI}^{100}{ }_{\mathrm{m} 3-0.075}, \mathrm{~F}_{100} \mathrm{FNSI}^{300}{ }_{\mathrm{m} 6-0.05}$, and $\mathrm{F}_{100} \mathrm{FNSI}^{600}{ }_{\mathrm{m} 9-0.0375}$ fibers, in which, the drawability and orientation of the best prepared fibers improved significantly as the specific surface areas of $\mathrm{FNSI}^{100}{ }_{\mathrm{m} 3}, \mathrm{FNSI}^{300}{ }_{\mathrm{m} 6}$, and FNSI $^{600}{ }_{\mathrm{m} 9}$ present in $\mathrm{F}_{100} \mathrm{FNSI}^{100}{ }_{\mathrm{m} 3-0.075}, \mathrm{~F}_{100} \mathrm{FNSI}^{300}{ }_{\mathrm{m} 6-0.05}$, and $\mathrm{F}_{100} \mathrm{FNSI}^{600}{ }_{\text {m9-0.0375 }}$ as-prepared and/or drawn fibers increased. However, the amounts of coagulated $\mathrm{NSI}^{x}$ and/or $\mathrm{FNSI}^{x}{ }_{\mathrm{m} y}$ particles are likely to increase significantly when their $\mathrm{NSI}^{x}$ and/or $\mathrm{FNSI}^{x}{ }_{\mathrm{m} y}$ contents are higher than certain values, respectively. These coagulated $\mathrm{NSI}^{x}$ and/or $\mathrm{FNSI}^{x}{ }_{\mathrm{m} y}$ particles can slide against each other and serve as the defects for stress concentration during the drawing processes of $\mathrm{F}_{100} \mathrm{NSI}_{z}^{x}$ and $\mathrm{F}_{100} \mathrm{FNSI}^{x}{ }_{\mathrm{m} y-z}$ as-prepared fibers and hence lead to an early breakage and/or significant reduction in achievable $\lambda$ and $f_{0}$ values of the resulting drawn fibers.
Based on these premises, it is reasonable to understand that the achievable $\lambda$ values of $\mathrm{F}_{100} \mathrm{NSI}^{x}{ }_{z}$ and $\mathrm{F}_{100} \mathrm{FNSI}^{x}{ }_{m y-z}$ as-prepared fibers and $f_{0}$ values of the drawn $\mathrm{F}_{100} \mathrm{NSI}^{x}{ }_{z}$ and $\mathrm{F}_{100} \mathrm{FNSI}^{x}{ }_{\mathrm{m} y-z}$ fibers with a fixed draw ratio reduce significantly when their $\mathrm{NSI}^{x}$ and/or $\mathrm{FNSI}^{x}{ }_{\mathrm{m} y}$ contents are higher than the specific optimal value, respectively.

3.7. Morphological Analyses of the As-Prepared and Drawn Fibers. Figure 7 exhibits typical SEM micrographs of the as-prepared and drawn $\mathrm{F}_{100}, \quad \mathrm{~F}_{100} \mathrm{FNSI}^{100}{ }_{\mathrm{m} 3-0.075}$, $\mathrm{F}_{100} \mathrm{FNSI}^{300}{ }_{\mathrm{m6}-0.05}$, and $\mathrm{F}_{100} \mathrm{FNSI}^{600}{ }_{\mathrm{mg}-0.0375}$ fibers with various draw ratios. Many demarcated drawn "microfibrils" were found paralleling the drawing direction of the drawn $\mathrm{F}_{100}, \mathrm{~F}_{100} \mathrm{FNSI}^{100}{ }_{\mathrm{m} 3-0.075}, \mathrm{~F}_{100} \mathrm{FNSI}^{300}{ }_{\mathrm{m} 6-0.05}$, and $\mathrm{F}_{100} \mathrm{FNSI}^{600}{ }_{\mathrm{m} 9-0.0375}$ fibers as their draw ratios increased, wherein the thicknesses of these drawn micro-fibrils reduced significantly as the draw ratios increased. Moreover, more and thinner "micro-fibrils" were found on the surfaces of $\mathrm{F}_{100} \mathrm{FNSI}^{100}{ }_{\mathrm{m} 3-0.075}, \quad \mathrm{~F}_{100} \mathrm{FNSI}^{300}{ }_{\mathrm{m} 6-0.05}$, and $\mathrm{F}_{100} \mathrm{FNSI}^{600}{ }_{\mathrm{m} 9-0.0375}$ as-prepared and/or drawn fibers with the same draw ratio as the specific surface areas of their $\mathrm{FNSI}_{\mathrm{m} 3}{ }^{100}, \mathrm{FNSI}_{\mathrm{m} 6}^{300}$, and $\mathrm{FNSI}_{\mathrm{m}}^{600}$ particles increased.

It is not completely clear what accounts for the interesting demarcated "micro-fibril" morphology found on the surfaces of $\mathrm{F}_{100}, \mathrm{~F}_{100} \mathrm{FNSI}^{100}{ }_{\mathrm{m} 3-0.075}, \mathrm{~F}_{100} \mathrm{FNSI}^{300}{ }_{\mathrm{m} 6-0.05}$, and $\mathrm{F}_{100} \mathrm{FNSS}^{600}{ }_{\mathrm{m} 9-0.0375}$ as-prepared and drawn fibers. Presumably, during the ultradrawing processes, many of 


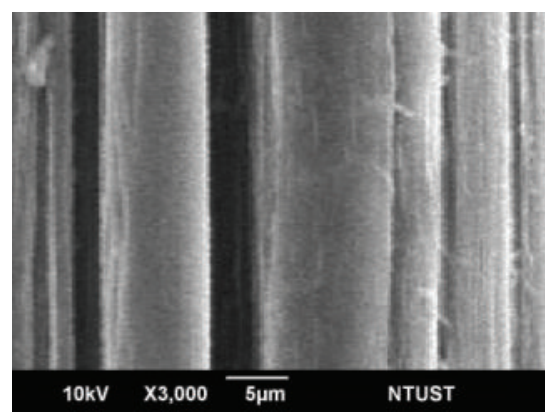

(a)

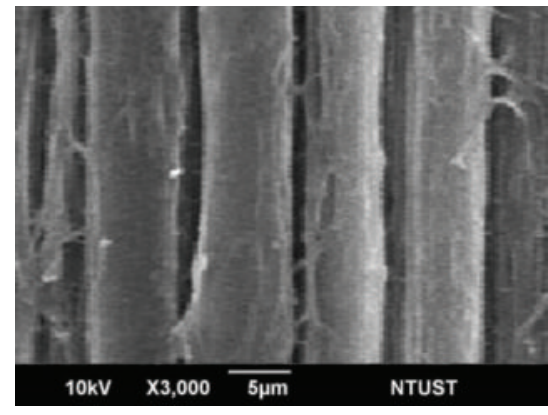

(d)

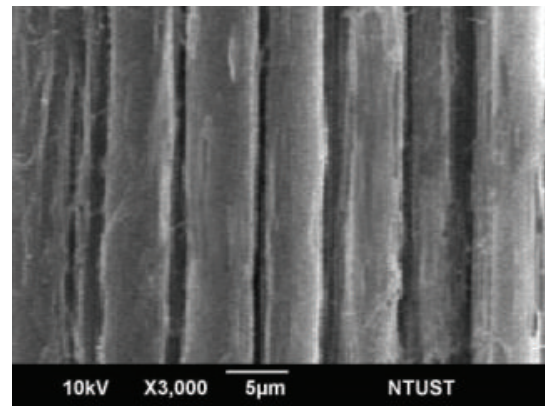

(g)

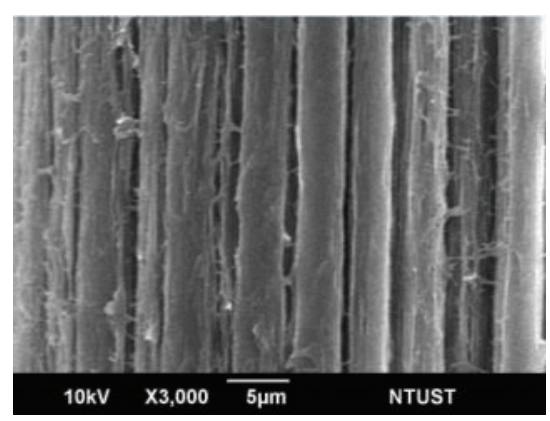

(j)

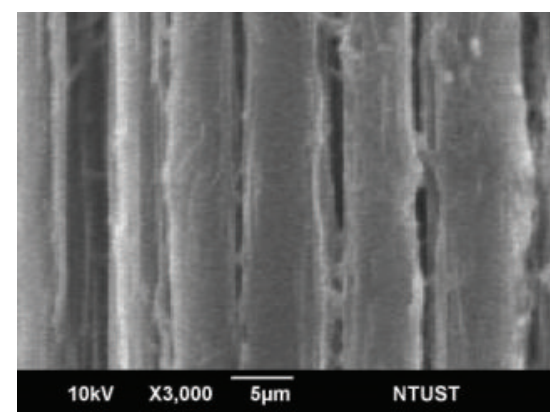

(b)

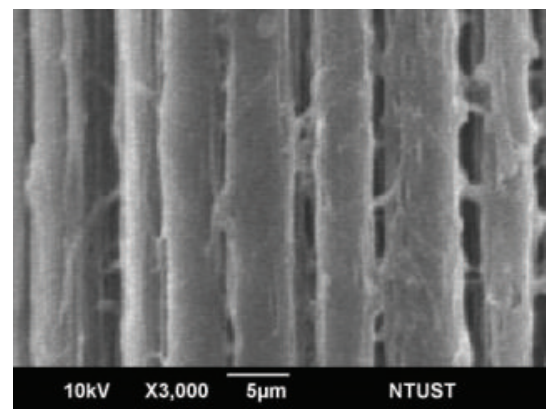

(e)

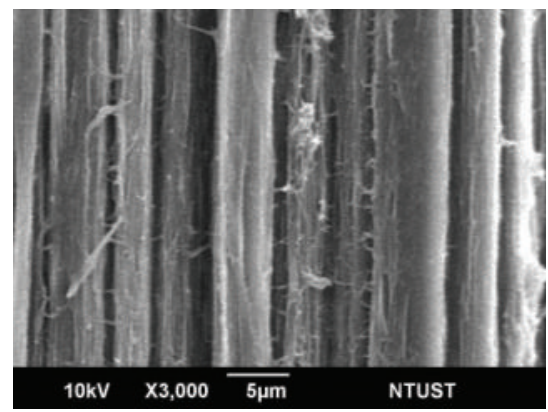

(h)

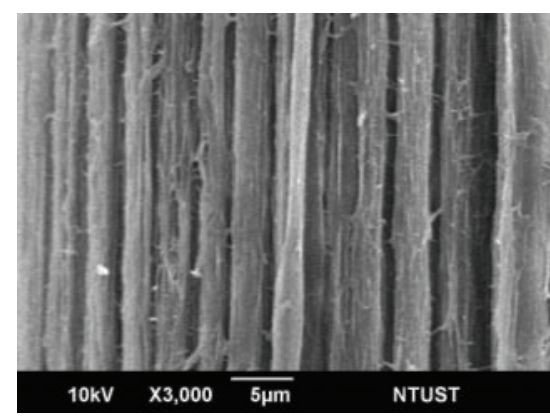

(k)

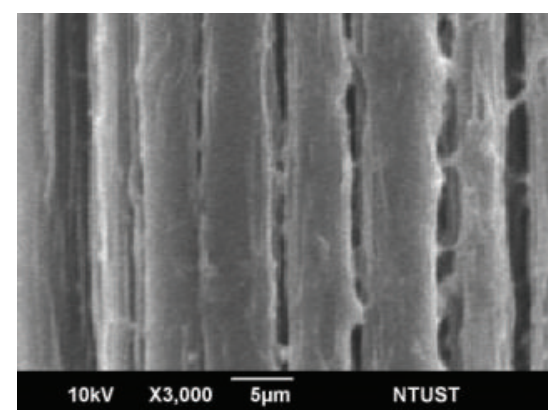

(c)

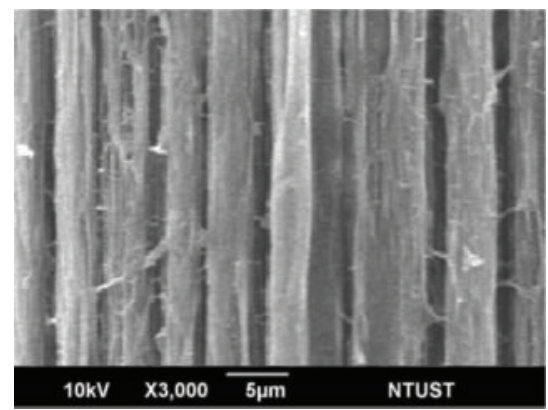

(f)

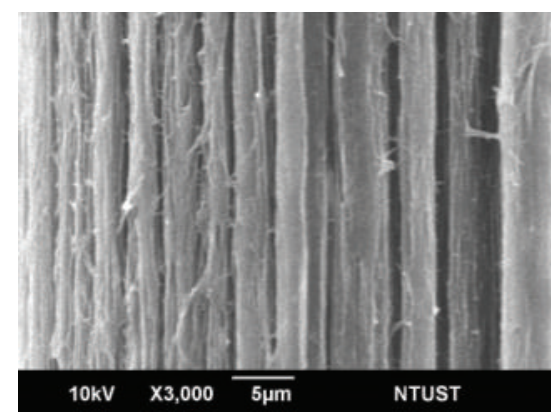

(i)

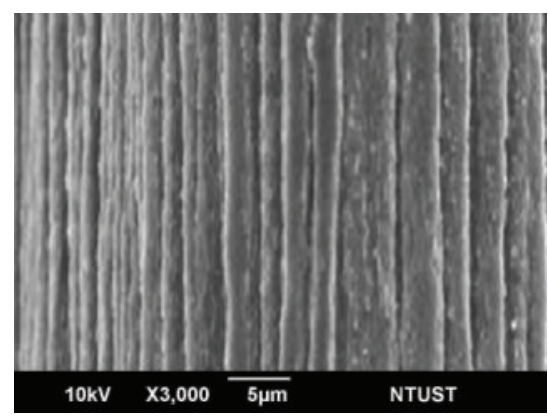

(1)

FIGURE 7: SEM micrographs of $\mathrm{F}_{100}$ fibers with a draw ratio of (a) 1 , (b) 50, and (c) 100; $\mathrm{F}_{100} \mathrm{FNSI}^{100}{ }_{\mathrm{m} 3-0.075}$ fibers with a draw ratio of (d) 1 , (e) 50 , and (f) 100; $\mathrm{F}_{100} \mathrm{FNSI}^{300}{ }_{\mathrm{m} 6-0.05}$ fibers with a draw ratio of $(\mathrm{g}) 1$, (h) 50, and (i) 100; and $\mathrm{F}_{100} \mathrm{FNSI}_{\mathrm{m} 9-0.0375}^{000}$ fibers with a draw ratio of (j) 1 , (k) 50, and (l) 100 .

the UHMWPE kebab crystals with relatively thinner lamellar thickness values can be unfolded and pulled out of the crystal lamellae in an easier way than those kebab crystals with thicker lamellar thickness values. The unfolded UHMWPE molecules pulled out from the kebab lamellae can then gradually transform into the oriented "micro-fibrils" during their ultradrawing processes. As evidenced by DSC analyses in the previous section, $T_{m}$ (or evaluated $l_{c}$ ) values of $\mathrm{F}_{100} \mathrm{NSI}^{x}{ }_{z}$ and/or $\mathrm{F}_{100} \mathrm{FNSI}^{x}{ }_{\mathrm{m} y-z}$ as-prepared fibers were significantly lower than that of $\mathrm{F}_{100}$ as-prepared fiber and reached a minimal value, as their $\mathrm{NSI}^{x}$ and/or $\mathrm{FNSI}^{x}{ }_{\mathrm{m} y}$ contents approached an optimal value, respectively, in 
which, the lowest $T_{m}$ (or evaluated $l_{c}$ ) values obtained for the best prepared $\mathrm{F}_{100} \mathrm{FNSI}^{100}{ }_{\mathrm{m} 3-0.075}, \mathrm{~F}_{100} \mathrm{FNSI}^{300}{ }_{\mathrm{m} 6-0.05}$, and $\mathrm{F}_{100} \mathrm{FNSI}^{600}{ }_{\mathrm{m} 9-0.0375}$ as-prepared fibers prepared at the optimal $\mathrm{FNSI}^{x}{ }_{\mathrm{m} y}$ contents and weight ratio of $\mathrm{PE}_{\mathrm{g}-\mathrm{MAH}}$ to $\mathrm{NSI}^{x}$ reduced significantly as the specific surface areas of their $\mathrm{FNSI}^{x}{ }_{\mathrm{m} y}$ particles increased. Based on these premises, it is reasonable to infer that the "micro-fibrils" found on the surfaces of as-prepared and/or drawn $\mathrm{F}_{100} \mathrm{FNSI}^{100} \mathrm{m3-0.075}$, $\mathrm{F}_{100} \mathrm{FNSI}^{300}{ }_{\mathrm{m} 6-0.05}$, and $\mathrm{F}_{100} \mathrm{FNSI}^{600}{ }_{\mathrm{m} 9-0.0375}$ fibers are more and thinner than those of the corresponding asprepared and/or drawn $\mathrm{F}_{100}$ fibers with the same draw ratios but without addition of any "nuclear" nanofillers. By the same analogy, more and thinner "micro-fibrils" are expected to be found on the surfaces of $\mathrm{F}_{100} \mathrm{FNSI}^{100} \mathrm{m3-0.075}$, $\mathrm{F}_{100} \mathrm{FNSI}^{300}{ }_{\mathrm{m} 6-0.05}$, and $\mathrm{F}_{100} \mathrm{FNSI}^{600}{ }_{\mathrm{m} 9-0.0375}$ as-prepared and/or drawn fibers as the specific surface areas of their $\mathrm{FNSI}^{x}{ }_{\mathrm{m} y}$ particles increased.

3.8. Tensile Properties. Tensile strength $\left(\sigma_{f}\right)$ and modulus (E) values of $\mathrm{F}_{100}, \mathrm{~F}_{100} \mathrm{NSI}^{x}{ }_{z}$, and $\mathrm{F}_{100} \mathrm{FNSI}^{x}{ }_{\mathrm{m} y-z}$ as-prepared fibers prepared at varying draw ratios are illustrated in Table 3. For comparison purposes, $\sigma_{f}$ and $E$ values of the best prepared UHMWPE/FCNT (i.e., $\mathrm{F}_{100} \mathrm{C}_{\mathrm{f} 2-0.1}$ ) as-prepared fiber obtained in our previous investigation [24] were also summarized in Table 3. As expected, $\sigma_{f}$ and $E$ values of the drawn $\mathrm{F}_{100}, \mathrm{~F}_{100} \mathrm{NSI}_{z}^{x}$, and $\mathrm{F}_{100} \mathrm{FNSI}^{x}{ }_{m y-z}$ fibers improve consistently as their draw ratios increase. It is worth noting that $\sigma_{f}$ and $E$ values of drawn $\mathrm{F}_{100} \mathrm{NSI}^{x}{ }_{z}$ and $\mathrm{F}_{100} \mathrm{FNSI}^{x}{ }_{\mathrm{m} y-z}$ fibers are significantly higher than those of the corresponding drawn $\mathrm{F}_{100}$ fibers with the same draw ratio but without addition of $\mathrm{NSI}^{x}$ and/or $\mathrm{FNSI}^{x}{ }_{\mathrm{m} y}$ particles. Similar to those found for their $f_{0}$ values, $\sigma_{f}$ and $E$ values of drawn $\mathrm{F}_{100} \mathrm{NSI}_{z}{ }_{z}$ and $\mathrm{F}_{100} \mathrm{FNSI}^{x}{ }_{\mathrm{m} y-z}$ fibers reach a maximal value as their $\mathrm{NSI}^{x}$ and/or $\mathrm{FNSI}^{x}{ }_{\mathrm{m} y}$ contents approach the optimal values at $0.075,0.05$, and $0.0375 \mathrm{phr}$, respectively, in which $\sigma_{f}$ and $E$ values of drawn $\mathrm{F}_{100} \mathrm{FNSI}_{\mathrm{m} y-0.075}, \mathrm{~F}_{100} \mathrm{FNSI}_{\mathrm{m} y-0.05}^{300}$, and $\mathrm{F}_{100} \mathrm{FNSI}^{600}{ }_{\mathrm{m} y-0.0375}$ fibers prepared at their optimal $\mathrm{FNSI}^{x}{ }_{\mathrm{m} y}$ contents are significantly higher than those of the corresponding drawn $\mathrm{F}_{100} \mathrm{NSI}^{100}{ }_{0.1}, \mathrm{~F}_{100} \mathrm{NSI}^{300}{ }_{0.0625}$, and $\mathrm{F}_{100} \mathrm{NSI}^{600}{ }_{0.05}$ fibers with the same draw ratio and an optimal $\mathrm{NSI}^{x}$ content at $0.1,0.0625$, and $0.05 \mathrm{phr}$, respectively. Moreover, at a fixed draw ratio, drawn $\mathrm{F}_{100} \mathrm{FNSI}^{100}{ }_{\mathrm{m} y-0.075}$, $\mathrm{F}_{100} \mathrm{FNSI}_{\mathrm{m} y-0.05}^{300}$, and $\mathrm{F}_{100} \mathrm{FNSI}_{\mathrm{m} y \text {-0.0375 }}^{600}$ fibers prepared at the optimal $\mathrm{FNSI}_{\mathrm{m} y}^{x}$ contents exhibited other maximal $\sigma_{f}$ and $E$ values, as their $\mathrm{FNSI}^{100}{ }_{\mathrm{m} y}, \mathrm{FNSI}^{300}{ }_{\mathrm{m} y}$, and $\mathrm{FNSI}^{600}{ }_{\mathrm{m} y}$ particles were modified using an optimal weight ratio of $\mathrm{PE}_{\mathrm{g}-\mathrm{MAH}}$ to $\mathrm{NSI}^{100}$, $\mathrm{NSI}^{300}$, and $\mathrm{NSI}^{600}$ at 3, 6, and 9, respectively. It is interesting to note that the maximal $\sigma_{f}$ and $E$ values obtained for the best prepared $\mathrm{F}_{100} \mathrm{FNSI}^{100}{ }_{\mathrm{m} 3-0.075}$, $\mathrm{F}_{100} \mathrm{FNSI}^{300}{ }_{\mathrm{m} 6-0.05}$, and $\mathrm{F}_{100} \mathrm{FNSI}^{600}{ }_{\mathrm{m} 9-0.0375}$ drawn fibers prepared at the optimal $\mathrm{FNSI}^{x}{ }_{\mathrm{m} y}$ contents and weight ratio of $\mathrm{PE}_{\mathrm{g}-\mathrm{MAH}}$ to $\mathrm{NSI}^{x}$ increased significantly as the specific surface areas of $\mathrm{FNSI}^{x}{ }_{\mathrm{m} y}$ particles increased. For instance, the ultimate $\sigma_{f}$ values of best prepared $\mathrm{F}_{100} \mathrm{FNSI}^{100}{ }_{\mathrm{m} 3-0.075}$,
$\mathrm{F}_{100} \mathrm{C}_{\mathrm{f} 2-0.1}, \quad \mathrm{~F}_{100} \mathrm{FNSI}^{300}{ }_{\mathrm{m} 6-0.05}, \quad$ and $\mathrm{F}_{100} \mathrm{FNSI}^{600}{ }_{\mathrm{m} 9-0.0375}$ fibers reached $4.4,5.1,7.1$, and $7.6 \mathrm{GPa}$, respectively, as the specific surface areas of FNSI ${ }_{\mathrm{m} 3}^{100}$, FCNT, $\mathrm{FNSI}_{\mathrm{m} y 6}^{300}$, and $\mathrm{FNSI}^{600} \mathrm{~m} 9$ particles increased from 129.8 to $272.7,335.8$ and to $630.7 \mathrm{~m}^{2} / \mathrm{g}$, respectively. The ultimate $\sigma_{f}$ value of the best prepared $\mathrm{F}_{100} \mathrm{FNSI}^{600}{ }_{\mathrm{m} 9-0.0375}$ drawn fiber is about 1.7 and 1.5 times of those of the $\mathrm{F}_{100} \mathrm{FNSI}^{100}{ }_{\mathrm{m} 3-0.075}$ and the best prepared UHMWPE/FCNT drawn fiber specimens, respectively, and is about 2.3 times of that of the best prepared UHMWPE drawn fibers prepared at the same optimal UHMWPE concentration and drawing condition but without addition of any nanofiller.

The mechanical properties of the drawn specimens are generally believed to depend mainly on the degree of orientation of the drawn specimens, as their molecular weights are constant $[16,34]$. As evidenced by orientation analyses in the previous section, at a fixed draw ratio, $f_{0}$ values of drawn $\mathrm{F}_{100} \mathrm{FNSI}^{100}{ }_{\mathrm{m} y-0.075}, \mathrm{~F}_{100} \mathrm{FNSI}_{\mathrm{m} y-0.05}^{300}$, and $\mathrm{F}_{100} \mathrm{FNSI}^{600}{ }_{\mathrm{m} y-0.0375}$ fibers prepared at the optimal $\mathrm{FNSI}_{\mathrm{m} y}{ }_{\mathrm{m}}$ contents were significantly higher than those of the corresponding $\mathrm{F}_{100} \mathrm{NSI}^{100}{ }_{0.1}, \mathrm{~F}_{100} \mathrm{NSI}^{300}{ }_{0.0625}$, and $\mathrm{F}_{100} \mathrm{NSI}^{600}{ }_{0.05}$ fibers prepared at an optimal $\mathrm{NSI}^{x}$ content, respectively. Moreover, $f_{0}$ values of $\mathrm{F}_{100} \mathrm{FNSI}^{100}{ }_{\mathrm{m} 3-0.075}, \mathrm{~F}_{100} \mathrm{FNSI}^{300}$ m6-0.05, and $\mathrm{F}_{100} \mathrm{FNSI}^{600}{ }_{\mathrm{m} 9-0.0375}$ drawn fibers were always higher than those of other $\mathrm{F}_{100} \mathrm{FNSI}_{\mathrm{m} y-0.075}, \mathrm{~F}_{100} \mathrm{FNSI}_{\mathrm{m} y-0.05}^{300}$, and $\mathrm{F}_{100} \mathrm{FNSI}_{\mathrm{m} y-0.0375}^{600}$ fibers prepared with the same draw ratios and FNSI contents but modified using an optimal weight ratio of $\mathrm{PE}_{\mathrm{g}-\mathrm{MAH}}$ to $\mathrm{NSI}^{100}, \mathrm{NSI}^{300}$, and $\mathrm{NSI}^{600}$ other than 3,6, and 9 , respectively. In fact, the maximal $f_{0}$ values obtained for the best prepared $\mathrm{F}_{100} \mathrm{FNSI}^{100}{ }_{\mathrm{m} 3-0.075}, \mathrm{~F}_{100} \mathrm{FNSI}^{300}{ }_{\mathrm{m} 6-0.05}$, and $\mathrm{F}_{100} \mathrm{FNSI}^{600}{ }_{\mathrm{m} 9-0.0375}$ drawn fibers improved significantly as the specific surface areas of their $\mathrm{FNSI}_{\mathrm{m} y}^{x}$ particles increased. These results clearly suggest that a good orientation of UHMWPE molecules along the drawing direction positively affects the tensile properties of $\mathrm{F}_{100}, \mathrm{~F}_{100} \mathrm{NSI}_{z}^{x}$, and $\mathrm{F}_{100} \mathrm{FNSI}^{x}{ }_{\mathrm{m} y-z}$ fibers. Excellent orientation and ultimate tensile properties of UHMWPE/nanofiller fibers can be prepared by the ultradrawing of $\mathrm{F}_{100} \mathrm{FNSI}_{\mathrm{m} y-z}$ asprepared fibers with optimal contents of the best prepared FNSI $^{100}{ }_{\mathrm{m} 3}$, $\mathrm{FNSI}_{\mathrm{m} 6}^{300}$, and $\mathrm{FNSI}_{\mathrm{m}}^{600}$ particles well dispersing in their as-prepared fibers. Moreover, the specific surface areas of well-dispersed functionalized nanofillers in UHMWPE/functionalized nanofiller fibers can positively affect their ultradrawing, orientation, ultimate tensile properties, and "micro-fibrils" morphologies.

\section{Conclusions}

As evidenced by FTIR and TEM analyses, $\mathrm{PE}_{\mathrm{g}-\mathrm{MAH}}$ molecules were successfully grafted onto nanosilica particles with varying specific surface areas through the reaction of the hydroxyl groups of nanosilica particles with the maleic anhydride groups of $\mathrm{PE}_{\mathrm{g}-\mathrm{MAH}}$ molecules during their functionalized processes. The specific surface areas of $\mathrm{FNSI}_{\mathrm{m} y}{ }^{100}, \mathrm{FNSI}_{\mathrm{m} y}^{300}$, and $\mathrm{FNSI}_{\mathrm{m} y}^{600}$ functionalized nanosilica particles reached a maximal value at 129.8, 335.8, 
TABLE 3: Tensile strength $\left(\sigma_{f}\right)$ and modulus values $(E)$ of UHMWPE $\left(\mathrm{F}_{100}\right)$, UHMWPE/functionalized nanosilica $\left(\mathrm{F}_{100} \mathrm{FNSI}^{x}{ }_{\mathrm{m} y-z}\right)$, and UHMWPE/carbon nanotube $\left(\mathrm{F}_{100} \mathrm{C}_{\mathrm{f} 2-0.1}\right)$ fiber specimens with varying draw ratios.

\begin{tabular}{|c|c|c|c|c|c|c|c|c|c|c|}
\hline \multirow{3}{*}{ Draw ratio } & \multicolumn{10}{|c|}{ Specimen } \\
\hline & \multicolumn{2}{|c|}{$\mathrm{F}_{100}$} & \multicolumn{2}{|c|}{$\mathrm{F}_{100} \mathrm{C}_{\mathrm{f} 2-0.1}$} & \multicolumn{2}{|c|}{$\mathrm{F}_{100} \mathrm{FNSI}_{\mathrm{m} 2-0.625}^{100}$} & \multicolumn{2}{|c|}{$\mathrm{F}_{100} \mathrm{FNSI}_{\mathrm{m} 2-0.075}^{100}$} & \multicolumn{2}{|c|}{$\mathrm{F}_{100} \mathrm{FNSI}_{\mathrm{m} 2-0.1}^{100}$} \\
\hline & $\sigma_{f}(\mathrm{GPa})$ & $E(\mathrm{GPa})$ & $\sigma_{f}(\mathrm{GPa})$ & $E(\mathrm{GPa})$ & $\sigma_{f}(\mathrm{GPa})$ & $E(\mathrm{GPa})$ & $\sigma_{f}(\mathrm{GPa})$ & $E(\mathrm{GPa})$ & $\sigma_{f}(\mathrm{GPa})$ & $E(\mathrm{GPa})$ \\
\hline 20 & 1.6 & 58.0 & 2.7 & 106.3 & 2.1 & 61.1 & 2.2 & 69.0 & 2.1 & 59.0 \\
\hline 40 & 1.9 & 71.2 & 3.5 & 140.5 & 2.6 & 80.7 & 2.8 & 90.3 & 2.8 & 77.8 \\
\hline 60 & 2.6 & 92.9 & 4.2 & 169.8 & 3.4 & 105.2 & 3.6 & 119.0 & 3.5 & 101.4 \\
\hline 120 & 3.4 & 112.5 & 4.9 & 194.5 & 4.0 & 118.5 & 4.2 & 130.2 & 4.0 & 115.9 \\
\hline 160 & - & - & 5.1 & 204.6 & 4.4 & 163.3 & 4.8 & 184.3 & 4.5 & 152.3 \\
\hline \multirow[t]{2}{*}{ Draw ratio } & \multicolumn{2}{|c|}{$\mathrm{F}_{100} \mathrm{FNSI}_{\mathrm{m} 3-0.625}$} & \multicolumn{2}{|c|}{$\mathrm{F}_{100} \mathrm{FNSI}_{\mathrm{m} 3-0.075}^{100}$} & \multicolumn{2}{|c|}{$\mathrm{F}_{100} \mathrm{FNSI}_{\mathrm{m} 3-0.1}^{100}$} & \multicolumn{2}{|c|}{$\mathrm{F}_{100} \mathrm{FNSI}_{\mathrm{m} 6-0.625}^{100}$} & \multicolumn{2}{|c|}{$\mathrm{F}_{100} \mathrm{FNSI}_{\mathrm{m} 6-0.075}^{100}$} \\
\hline & $\sigma_{f}(\mathrm{GPa})$ & $E(\mathrm{GPa})$ & $\sigma_{f}(\mathrm{GPa})$ & $E(\mathrm{GPa})$ & $\sigma_{f}(\mathrm{GPa})$ & $E(\mathrm{GPa})$ & $\sigma_{f}(\mathrm{GPa})$ & $E(\mathrm{GPa})$ & $\sigma_{f}(\mathrm{GPa})$ & $E(\mathrm{GPa})$ \\
\hline 20 & 2.4 & 73.1 & 2.5 & 81.0 & 2.4 & 71.0 & 2.2 & 67.1 & 2.3 & 75.0 \\
\hline 40 & 2.9 & 92.7 & 3.1 & 102.3 & 3.1 & 89.8 & 2.7 & 86.7 & 2.9 & 96.3 \\
\hline 60 & 3.7 & 117.2 & 3.9 & 131.0 & 3.8 & 113.4 & 3.5 & 111.2 & 3.7 & 125.0 \\
\hline 120 & 4.3 & 130.5 & 4.5 & 142.2 & 4.3 & 127.9 & 4.1 & 124.5 & 4.3 & 136.2 \\
\hline 160 & 4.6 & 175.3 & 5.0 & 196.3 & 4.8 & 164.3 & 4.4 & 169.3 & 4.8 & 190.3 \\
\hline \multirow[t]{2}{*}{ Draw ratio } & \multicolumn{2}{|c|}{$\mathrm{F}_{100} \mathrm{FNSI}_{\mathrm{m} 6-0.1}^{100}$} & $\mathrm{~F}_{100} \mathrm{FNSI}_{\mathrm{m} 3-0.375}^{300}$ & \multicolumn{4}{|c|}{ Specimen } & $\mathrm{F}_{100} \mathrm{FNSI}_{\mathrm{m} 3-0.075}^{300}$ & \multicolumn{2}{|c|}{$\mathrm{F}_{100} \mathrm{FNSI}^{300}{ }_{\mathrm{m} 6-0.375}$} \\
\hline & $\sigma_{f}(\mathrm{GPa})$ & $E(\mathrm{GPa})$ & $\sigma_{f}(\mathrm{GPa})$ & $E(\mathrm{GPa})$ & $\sigma_{f}(\mathrm{GPa})$ & $E(\mathrm{GPa})$ & $\sigma_{f}(\mathrm{GPa})$ & $E(\mathrm{GPa})$ & $\sigma_{f}(\mathrm{GPa})$ & $E(\mathrm{GPa})$ \\
\hline 20 & 2.2 & 65.0 & 2.5 & 79.3 & 2.6 & 84.2 & 2.3 & 75.9 & 2.9 & 93.3 \\
\hline 40 & 2.9 & 83.8 & 3.2 & 108.3 & 3.3 & 112.9 & 2.8 & 102.9 & 3.6 & 122.3 \\
\hline 60 & 3.6 & 107.4 & 4.1 & 151.7 & 4.2 & 156.7 & 3.9 & 147.0 & 4.5 & 165.7 \\
\hline 120 & 4.1 & 121.9 & 4.7 & 172.7 & 4.9 & 176.9 & 4.4 & 167.6 & 5.1 & 186.7 \\
\hline 160 & 4.6 & 158.3 & 5.7 & 184.9 & 5.8 & 187.9 & 5.5 & 183.9 & 6.1 & 198.9 \\
\hline 200 & - & - & 6.0 & 188.1 & 6.1 & 192.6 & 5.9 & 189.2 & 6.4 & 202.1 \\
\hline \multirow[t]{2}{*}{ Draw ratio } & $\mathrm{F}_{100} \mathrm{FN}$ & ${ }^{300}{ }_{\mathrm{m} 6-0.5}$ & $\mathrm{~F}_{100} \mathrm{FNS}$ & ${ }_{\mathrm{m} 6-0.075}$ & $\begin{array}{r}\text { Spec } \\
\mathrm{F}_{100} \mathrm{FNS}\end{array}$ & $\begin{array}{l}\text { nen } \\
\operatorname{lo}_{\mathrm{m} 9-0.375}\end{array}$ & $\mathrm{~F}_{100} \mathrm{FN}$ & ${ }_{\mathrm{m} 9-0.5}$ & $\mathrm{~F}_{100} \mathrm{FNS}$ & ${ }_{\mathrm{m} 9-0.075}^{0}$ \\
\hline & $\sigma_{f}(\mathrm{GPa})$ & $E(\mathrm{GPa})$ & $\sigma_{f}(\mathrm{GPa})$ & $E(\mathrm{GPa})$ & $\sigma_{f}(\mathrm{GPa})$ & $E(\mathrm{GPa})$ & $\sigma_{f}(\mathrm{GPa})$ & $E(\mathrm{GPa})$ & $\sigma_{f}(\mathrm{GPa})$ & $E(\mathrm{GPa})$ \\
\hline 20 & 3.0 & 98.2 & 2.7 & 89.9 & 2.6 & 86.3 & 2.7 & 91.2 & 2.4 & 82.9 \\
\hline 40 & 3.7 & 126.9 & 3.2 & 116.9 & 3.3 & 115.3 & 3.4 & 119.9 & 2.9 & 109.9 \\
\hline 60 & 4.6 & 170.7 & 4.3 & 161.0 & 4.2 & 158.7 & 4.3 & 163.7 & 4.0 & 154.0 \\
\hline 120 & 5.3 & 190.9 & 4.8 & 181.6 & 4.8 & 179.7 & 5.0 & 183.9 & 4.5 & 174.6 \\
\hline 160 & 6.2 & 201.9 & 5.9 & 197.9 & 5.8 & 191.9 & 5.9 & 194.9 & 5.6 & 190.9 \\
\hline 200 & 6.5 & 206.6 & 6.3 & 203.2 & 6.1 & 195.1 & 6.2 & 199.6 & 6.0 & 196.2 \\
\hline Draw ratio & $\mathrm{F}_{100} \mathrm{FNS}$ & ${ }_{\mathrm{m} 6-0.025}$ & $\mathrm{~F}_{100} \mathrm{FNS}$ & ${ }_{\mathrm{m} 6-0.0375}$ & $\begin{array}{r}\text { Spec } \\
\mathrm{F}_{100} \mathrm{FNS}\end{array}$ & $\begin{array}{l}\text { nen } \\
{ }_{00}{ }_{\text {m6-0.05 }}\end{array}$ & $\mathrm{F}_{100} \mathrm{FNS}$ & $\mathrm{m} 9-0.025$ & $\mathrm{~F}_{100} \mathrm{FNS}$ & ${ }_{\mathrm{m} 9-0.0375}$ \\
\hline & $\sigma_{f}(\mathrm{GPa})$ & $E(\mathrm{GPa})$ & $\sigma_{f}(\mathrm{GPa})$ & $E(\mathrm{GPa})$ & $\sigma_{f}(\mathrm{GPa})$ & $E(\mathrm{GPa})$ & $\sigma_{f}(\mathrm{GPa})$ & $E(\mathrm{GPa})$ & $\sigma_{f}(\mathrm{GPa})$ & $E(\mathrm{GPa})$ \\
\hline 20 & 2.5 & 93.5 & 2.8 & 101.2 & 2.6 & 96.5 & 2.9 & 109.5 & 3.2 & 117.2 \\
\hline 40 & 3.2 & 116.7 & 3.5 & 128.1 & 3.3 & 126.1 & 3.6 & 132.7 & 3.9 & 144.1 \\
\hline 60 & 4.3 & 156.8 & 4.4 & 163.4 & 4.3 & 158.8 & 4.7 & 172.8 & 4.8 & 179.4 \\
\hline 120 & 4.9 & 181.5 & 5.2 & 190.8 & 5.0 & 184.1 & 5.3 & 197.5 & 5.6 & 206.8 \\
\hline 160 & 6.0 & 221.2 & 6.2 & 227.4 & 6.1 & 223.9 & 6.4 & 237.2 & 6.6 & 243.4 \\
\hline 200 & 6.2 & 230.5 & 6.4 & 236.4 & 6.4 & 234.8 & 6.6 & 246.5 & 6.8 & 252.4 \\
\hline 240 & 6.5 & 239.7 & 6.6 & 245.7 & 6.5 & 241.4 & 6.9 & 255.7 & 7.0 & 261.7 \\
\hline 280 & 6.6 & 244.9 & 6.8 & 247.2 & 6.6 & 245.0 & 7.0 & 260.9 & 7.1 & 263.2 \\
\hline 320 & - & - & - & - & - & - & - & - & 7.2 & 266.0 \\
\hline 360 & - & - & - & - & - & - & - & - & 7.4 & 273.7 \\
\hline
\end{tabular}


TABLE 3: Continued.

\begin{tabular}{|c|c|c|c|c|c|c|c|c|c|}
\hline \multirow{3}{*}{ Draw ratio } & \multicolumn{9}{|c|}{ Specimen } \\
\hline & \multicolumn{2}{|c|}{$\mathrm{F}_{100} \mathrm{FNSI}^{600}{ }_{\mathrm{m} 9-0.05}$} & \multicolumn{2}{|c|}{$\mathrm{F}_{100} \mathrm{FNSI}^{600}{ }_{\mathrm{m} 12-0.025}$} & \multicolumn{2}{|c|}{$\mathrm{F}_{100} \mathrm{FNSI}^{600}{ }_{\mathrm{ml2}-0.0375}$} & \multicolumn{2}{|c|}{$\mathrm{F}_{100} \mathrm{FNSI}_{\mathrm{ml2}-0.05}^{600}$} & \multirow{2}{*}{-} \\
\hline & $\sigma_{f}(\mathrm{GPa})$ & $E(\mathrm{GPa})$ & $\sigma_{f}(\mathrm{GPa})$ & $E(\mathrm{GPa})$ & $\sigma_{f}(\mathrm{GPa})$ & $E(\mathrm{GPa})$ & $\sigma_{f}(\mathrm{GPa})$ & $E(\mathrm{GPa})$ & \\
\hline 20 & 3.0 & 112.5 & 2.4 & 100.5 & 3.0 & 108.2 & 2.8 & 103.5 & - \\
\hline 40 & 3.8 & 142.1 & 3.4 & 123.7 & 3.7 & 135.1 & 3.6 & 133.1 & - \\
\hline 60 & 4.7 & 174.8 & 4.5 & 163.8 & 4.6 & 170.4 & 4.5 & 165.8 & - \\
\hline 120 & 5.4 & 200.1 & 5.1 & 188.5 & 5.4 & 197.8 & 5.2 & 191.1 & - \\
\hline 160 & 6.5 & 239.9 & 6.2 & 228.2 & 6.4 & 234.4 & 6.3 & 230.9 & - \\
\hline 200 & 6.8 & 250.8 & 6.4 & 237.5 & 6.6 & 243.4 & 6.6 & 241.8 & - \\
\hline 240 & 6.9 & 257.4 & 6.7 & 246.7 & 6.8 & 252.7 & 6.7 & 248.4 & - \\
\hline 280 & 7.0 & 261.0 & 6.8 & 251.9 & 6.9 & 254.2 & 6.8 & 252.0 & - \\
\hline 320 & - & 一 & - & - & 7.0 & 257.0 & - & - & - \\
\hline
\end{tabular}

and $630.7 \mathrm{~m}^{2} / \mathrm{g}$, respectively, as the weight ratios of $\mathrm{PE}_{\mathrm{g}-\mathrm{MAH}}$ to $\mathrm{NSI}^{100}$, $\mathrm{NSI}^{300}$, and $\mathrm{NSI}^{600}$ nanosilica particles of $\mathrm{FNSI}_{\mathrm{m} y}^{100}, \mathrm{FNSI}_{\mathrm{m} y}^{300}$, and $\mathrm{FNSI}_{\mathrm{m} y}^{600}$ functionalized nanosilica particles approached an optimal value at 3 , 6 , and 9, respectively. The specific surface areas of welldispersed functionalized nanosilica particles in UHMWPE/ functionalized nanosilica fibers were found to affect positively on the achievable $\lambda$, percentage crystallinity, ultimate tensile strength values, and "micro-fibrils" morphologies of the UHMWPE/functionalized nanosilica as-prepared fibers. The achievable $\lambda$ values of the best prepared UHMWPE/functionalized nanosilica as-prepared fibers (i.e., $\mathrm{F}_{100} \mathrm{FNSI}^{100}{ }_{\mathrm{m} 3-0.075}, \mathrm{~F}_{100} \mathrm{FNSI}^{300}$ m6-0.05, and $\mathrm{F}_{100} \mathrm{FNSI}^{600}{ }_{\mathrm{m} 9-0.0375}$ ) improved consistently from 176 to 289 and 361, as the specific surface areas of the incorporated functionalized nanosilica particles increased from 129.8 to 335.8 and $630.7 \mathrm{~m}^{2} / \mathrm{g}$, respectively. Similar to those found for the achievable drawing properties of the best prepared UHMWPE/functionalized nanosilica as-prepared fibers, the orientation factor, ultimate $\sigma_{f}$ and $E$ values of the best prepared UHMWPE/functionalized nanosilica drawn fibers (i.e., $\mathrm{F}_{100} \mathrm{FNSI}_{\mathrm{m} 3-0.075}{ }^{100} \quad \mathrm{~F}_{100} \mathrm{FNSI}^{300}{ }_{\mathrm{m} 6-0.05}$, and $\mathrm{F}_{100} \mathrm{FNSI}^{600}{ }_{\mathrm{m} 9-0.0375}$ ) with a fixed draw improved positively, as the specific surface areas of added functionalized nanosilica particles increased from 129.8 to 335.8 and $630.7 \mathrm{~m}^{2} / \mathrm{g}$. For instance, the ultimate $\sigma_{f}$ values of the best prepared UHMWPE/functionalized nanosilica drawn fibers improved significantly from 4.4 to 7.1 and $7.6 \mathrm{GPa}$, respectively, as the specific surface areas of functionalized nanosilica particles increased from 129.8 to 335.8 and $630.7 \mathrm{~m}^{2} / \mathrm{g}$, respectively. The maximal ultimate $\sigma_{f}$ value (i.e., 7.6 GPa) of the best prepared UHMWPE/functionalized nanosilica drawn fiber with the highest specific surface area of functionalized nanosilica is about 2.3 times of that of the best prepared UHMWPE drawn fiber prepared at the same optimal UHMWPE concentration and drawing condition but without addition of any nanofiller. The "micro-fibrils" found on the surfaces of UHMWPE/functionalized nanosilica drawn fibers with the same draw ratio became more and thinner as the specific surface areas of their functionalized nanosilica particles increased. Possible reasons accounting for the above interesting properties were reported in this study.

\section{Conflict of Interests}

The authors declare that there is no conflict of interests regarding the publication of this paper.

\section{Acknowledgments}

The authors would like to express their appreciation to the Department of Industrial Technology, Ministry of Economic Affairs (99-EC-17-A-11-S1-155, 100-EC-17-A-11-S1-155, and 101EC-17-A-11-S1-155), and National Science Council (NSC 992221-E-011-010-MY3 and NSC 102-2221-E-168-038-MY3) for support of this work.

\section{References}

[1] K. Kajiwara and J. E. Mcintyre, Advanced Fibre Spinning Technology, Woodhead Publishing, Cambridge, UK, 1994.

[2] C. Xiao, Y. Zhang, S. An, and G. Jia, "Investigation on the thermal behaviors and mechanical properties of ultrahigh molecular weight polyethylene (UHMW-PE) fibers," Journal of Applied Polymer Science, vol. 59, no. 6, pp. 931-935, 1996.

[3] M. I. Abo El-Maaty, R. H. Olley, and D. C. Bassett, "On the internal morphologies of high-modulus polyethylene and polypropylene fibres," Journal of Materials Science, vol. 34, no. 9, pp. 1975-1989, 1999.

[4] K. Yamaura, M. Suzuki, M. Yamamoto, R. Shimada, and T. Tanigami, "Gelation of poly(vinyl alcohol)/phenol/water solutions and gel spinning," Journal of Applied Polymer Science, vol. 58, no. 10, pp. 1787-1791, 1995.

[5] X. Zhang, T. Liu, T. V. Sreekumar, S. Kumar, X. Hu, and K. Smith, "Gel spinning of PVA/SWNT composite fiber," Polymer, vol. 45, no. 26, pp. 8801-8807, 2004.

[6] O. Darras, R. Seguela, and F. Rietsch, "Dried gels from linear low-density polyethylene: morphology, thermal behavior, and mechanical properties," Journal of Polymer Science Part B: Polymer Physics, vol. 30, no. 4, pp. 349-359, 1992.

[7] J. Yeh and S. Chang, "Ultradrawing behavior of gel films of ultrahigh molecular weight polyethylene and low molecular 
weight polyethylene blends at varying drawing conditions," Polymer Engineering \& Science, vol. 42, no. 7, pp. 1558-1567, 2002.

[8] J.-T. Yeh, Y.-T. Lin, and H.-B. Jiang, "Drawing properties of ultrahigh molecular weight polyethylene fibers prepared at varying formation temperatures," Journal of Applied Polymer Science, vol. 91, no. 3, pp. 1559-1570, 2004.

[9] J. T. Yeh, Y. T. Lin, and K. N. Chen, "Ultradrawing properties of gel films of ultrahigh-molecular-weight polyethylene and lowmolecular-weight polyethylene blends prepared at various formation temperatures," Journal of Applied Polymer Science, vol. 89, no. 14, pp. 3728-3738, 2003.

[10] P. Smith, H. D. Chanzy, and B. P. Rotzinger, "Drawing of virgin ultrahigh molecular weight polyethylene: an alternative route to high strength/high modulus materials," Journal of Materials Science, vol. 22, no. 2, pp. 523-531, 1987.

[11] P. Smith, H. D. Chanzy, and B. P. Rotzinger, "Drawing of virgin UHMW polyethylene: an alternative route to high strength/ high modulus materials," Journal of Materials Science, vol. 22, pp. 523-531, 1987.

[12] M. Matsuo, C. Sawatari, M. Iida, and M. Yoneda, "Ultradrawing of high molecular weight polyethylene films produced by gelation/crystallization from solution: effect of the number of entanglements," Polymer Journal, vol. 17, no. 11, pp. 1197-1208, 1985.

[13] T. Kanamoto, A. Tsurta, K. Tanana, M. Takeda, and R. S. Porter, "Super-drawing of ultrahigh molecular weight polyethylene. 1. Effect of techniques on drawing of single crystal mats," Macromolecules, vol. 21, no. 2, pp. 470-477, 1988.

[14] J. Smook and A. J. Pennings, "The effect of temperature and deformation rate on the hot-drawing behavior of porous highmolecular-weight polyethylene fibers," Journal of Applied Polymer Science, vol. 27, no. 6, pp. 2209-2228, 1982.

[15] T. Jian, W.-D. Shyu, Y.-T. Lin, K.-N. Chen, and J.-T. Yeh, "Spinning and drawing properties of ultrahigh-molecular-weight polyethylene fibers prepared at varying concentrations and temperatures," Polymer Engineering and Science, vol. 43, no. 11, pp. 1765-1777, 2003.

[16] T. Ohta, "Review on processing ultra high tenacity fibers from flexible polymer," Polymer Engineering and Science, vol. 23, no. 13, pp. 697-703, 1983.

[17] D. C. Prevorsek, Polymer Liquid Crystals, Academic Press, London, UK, 1982.

[18] B. Kalb and A. J. Pennings, "Hot drawing of porous high molecular weight polyethylene," Polymer, vol. 21, no. 1, pp. 3-4, 1980.

[19] M. A. Wilding and I. M. Ward, "Tensile creep and recovery in ultra-high modulus linear polyethylenes," Polymer, vol. 19, no. 8, pp. 969-976, 1978.

[20] P. Smith and P. J. Lemstra, "Ultra-high strength polyethylene filaments by solution spinning/drawing. 3. Influence of drawing temperature," Polymer, vol. 21, no. 11, pp. 1341-1343, 1980.

[21] S. Kavesh and D. C. Prevorsek, US Patent 4536536, 1985.

[22] S. Kavesh and D. C. Prevorsek, "Producing high tenacity, high modulus crystalline article such as fiber or film," US Patent 4551296, 1985.

[23] S. Kavesh and D. C. Prevorsek, "High tenacity, high modulus polethylene and polypropylene fibers and intermediates therefore," US Patent 4413110, 1983.

[24] J.-T. Yeh, T.-W. Wu, Y.-C. Lai et al., "Ultradrawing properties of ultra-high molecular weight polyethylene/functionalized carbon nanotube fibers," Polymer Engineering \& Science, vol. 51, no. 4, pp. 687-696, 2011.

[25] J.-T. Yeh, C.-K. Wang, P. Hu, Y.-C. Lai, L.-K. Huang, and F.-C. Tsai, "Ultradrawing properties of ultrahigh-molecular-weight polyethylene/attapulgite fibers," Polymer International, vol. 61, no. 6, pp. 982-989, 2012.

[26] J.-T. Yeh, C.-K. Wang, A. Yeh et al., "Preparation and characterization of novel ultra-high molecular weight polyethylene composite fibers filled with nanosilica particles," Polymer International, vol. 62, no. 4, pp. 591-600, 2013.

[27] J. T. Yeh, C. C. Tsai, C. K. Wang, J. W. Shao, M. Z. Xiao, and S. C. Chen, "Ultradrawing novel ultra-high molecular weight polyethylene fibers filled with bacterial cellulose nanofibers," Carbohydrate Polymers, vol. 101, pp. 1-10, 2014.

[28] J. D. Hoffman and R. L. Miller, "Kinetic of crystallization from the melt and chain folding in polyethylene fractions revisited: theory and experiment," Polymer, vol. 38, no. 13, pp. 3151-3212, 1997.

[29] J. D. Hoffman and J. J. Weeks, "Rate of spherulitic crystallization with chain folds in polychlorotrifluoroethylene," Journal of Research of the National Bureau of Standards, vol. 66, p. 13, 1962.

[30] H. Xiao, Y. Zhang, S. An, and G. Jia, "Investigation on the thermal behaviors and mechanical properties of ultrahigh molecular weight polyethylene (UHMW-PE) fibers," Journal of Applied Polymer Science, vol. 59, no. 6, pp. 931-935, 1997.

[31] D. A. Skoog and J. J. Leary, Principles of Instrumental Analysis, Saunders College Publishing, 6th edition, 2006.

[32] Technical Textiles International, vol. 4, Knitting International, 1996.

[33] P. Smith and P. J. Lemstra, "Ultra-high-strength polyethylene filaments by solution spinning/drawing," Journal of Materials Science, vol. 15, no. 2, pp. 505-514, 1980.

[34] W. Hoogsteen, G. T. Brinke, and A. J. Pennings, "DSC experiments on gel-spun polyethylene fibers," Colloid and Polymer Science, vol. 266, no. 11, pp. 1003-1013, 1988. 

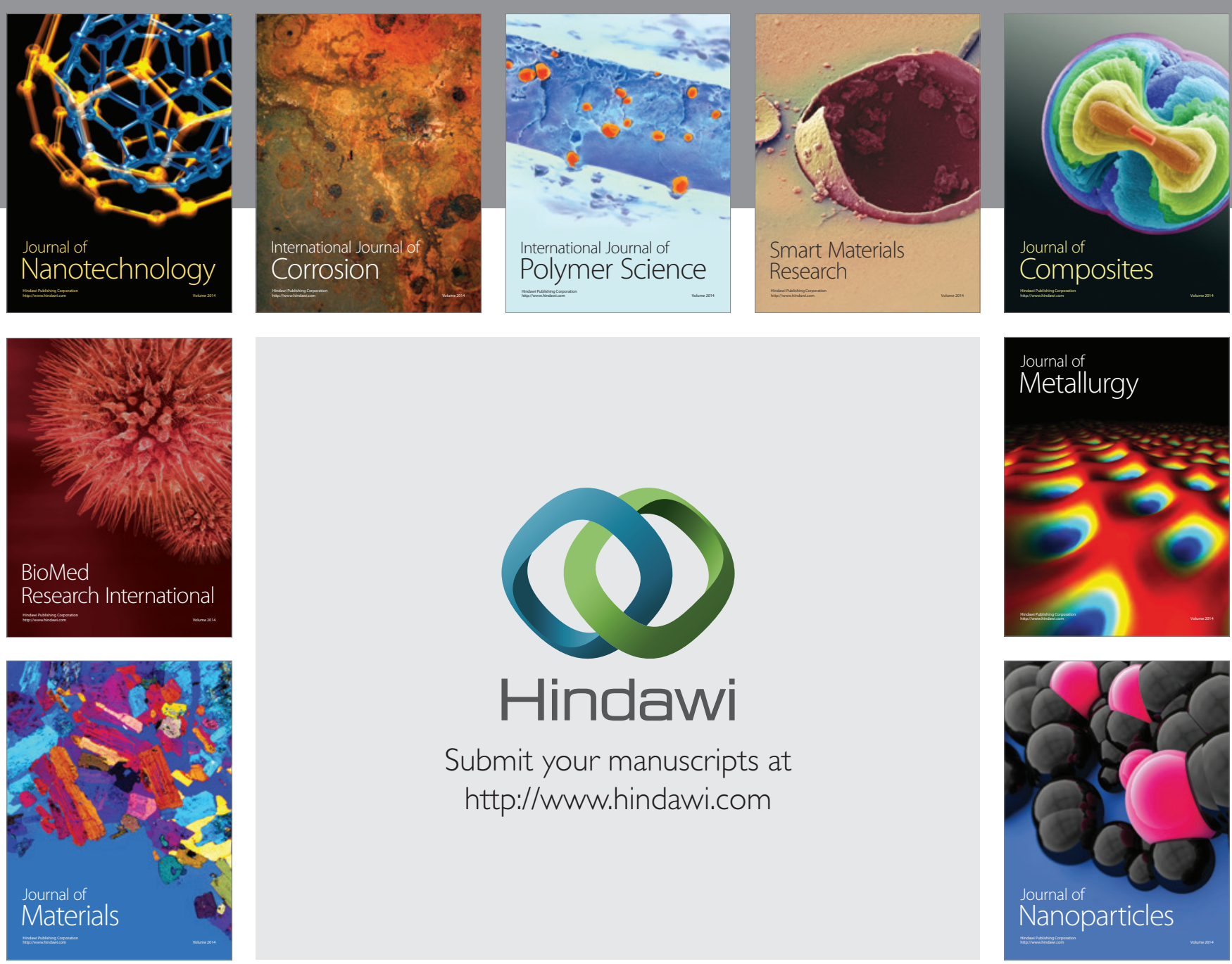

Submit your manuscripts at http://www.hindawi.com
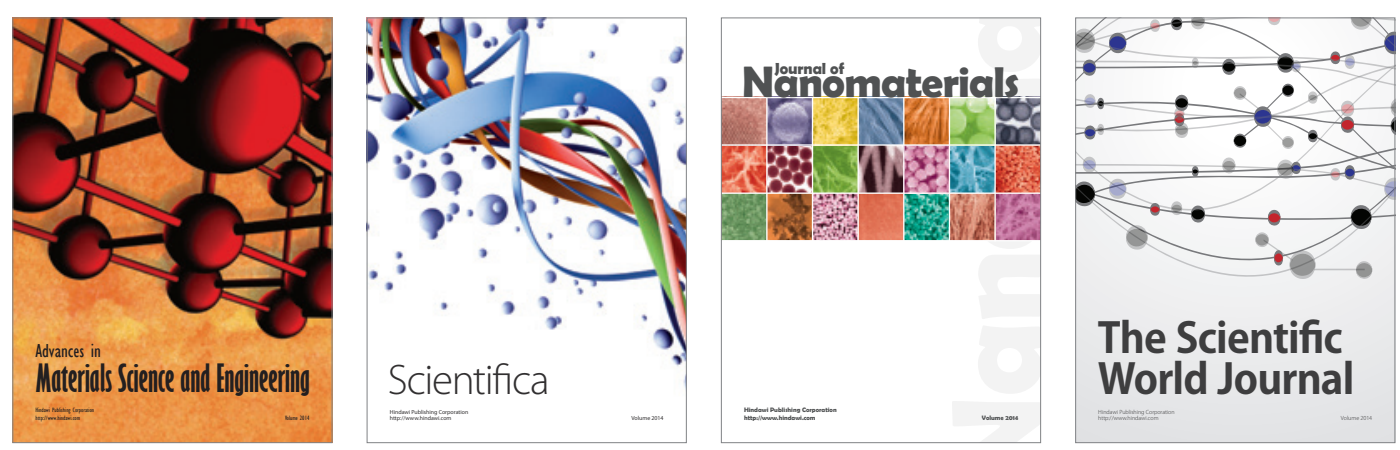

\section{The Scientific World Journal}
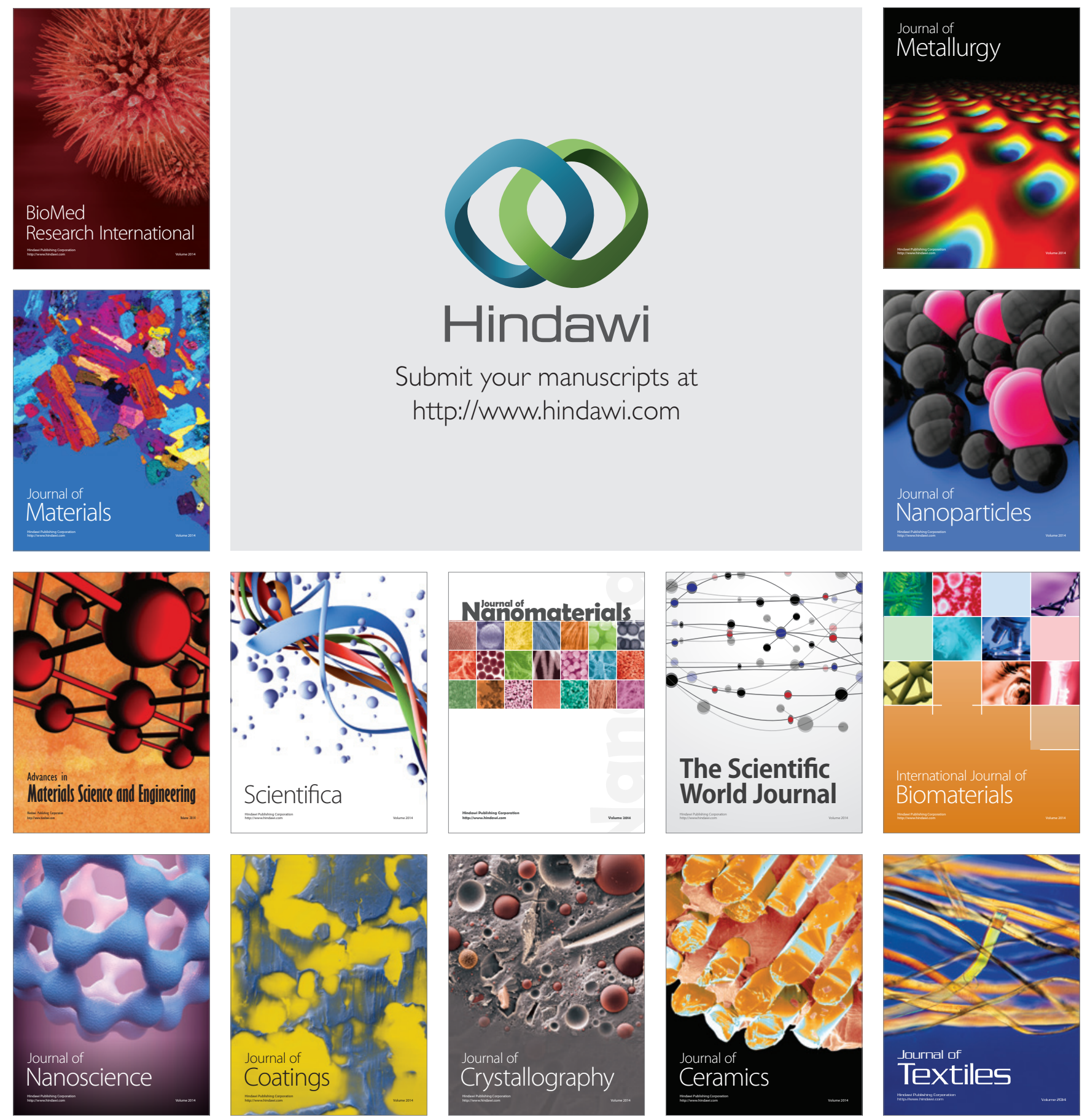